\title{
Mobile LiDAR for underground geomechanics: learnings from the teens and directions for the twenties
}

\author{
EW Jones Curtin University and BHP, Australia
}

\begin{abstract}
Mobile LiDAR mapping techniques took a vast step forward during the twenty-teens, from research and development to consumer products. The promise of spatially mapping GPS-denied environments opened a world of possibilities; applications in underground geomechanics has been just one. The sensor technology and associated hardware has improved immensely and the future promises exciting developments. However, the data acquisition is only the first step in what is a whole new workflow applied to underground mining geomechanics. The workflow from data acquisition to final interpretation is not currently an automated, algorithmic process. Rather, it currently requires a conceptual understanding of the hardware, and various data processing methods to arrive at implementable results. The technology provides a valuable tool for aiding mining and geomechanical engineers. Its advantages include greater spatial coverage, detailed rock mass assessments, and safe access to previously inaccessible areas. The twenty-twenties hold great promise for the technology.

This paper details the background to how mobile mapping technology has been introduced into underground mining geomechanics. The hardware and processing limitations are discussed with reference to case examples from the author's experience using the technology. Finally, some speculation is offered into the hardware developments and industry adoption over the coming years.
\end{abstract}

Keywords: mobile LiDAR, SLAM, monitoring, geomechanics

\section{Introduction}

Lasers were developed 60 years ago in the Hughes Research Lab in Malibu, California. On 16 May 1960, Theodore Maiman produced a single ruby $0.694 \mu \mathrm{m}$ laser (Maiman 1960), beating fellow American researchers, Canadians (12 January 1961) and Russians (June 1961) to the accomplishment (Nelson 2014). The single-shot lasers were soon overtaken by continuous wave lasers by Bell Laboratories in December 1960 and commercial instruments become available by 1961 . The research and applications of laser technology rapidly increased through the 1960s. Pulsed lasers (the type used in mobile LiDAR applications) were proposed in 1961 and by 1969, they were being trialled for airborne bathymetric mapping (Hickman \& Hogg 1969). This early feasibility research by Hickman \& Hogg on Lake Ontario's shore used 1,000 pulses per second.

Throughout the 1970s, the applications using LiDAR increased and included military, space exploration, medical, and forestry industries. However, in pre-GPS times the ability to georeference data was limited; LiDAR was cross-referenced to photo-mosaics. Arp et al. (1982) reported on one of the larger projects using this technique for a reservoir placement, where $800 \mathrm{~km}^{2}$ of Venezualan jungle was mapped using airborne LiDAR. The time to topographically map that area by foot would been approximately 34 years; Arp et al.'s LiDAR approach took five months. Arp et al.'s paper describes the difficulties of georeferencing their data, cross-correlating known markers in photos to standard locations in each scan. Both the plane altitude and variances in canopy reflectivity affected the alignment. The result, after five months, was an $800 \mathrm{~km}^{2}$, 1:25,000 topographic survey to an accuracy of approximately 2-2.5 m. Arp et al. (1982) concluded that "The procedure and instrumentation... appear to offer a rapid, economical and satisfactory solution to the problem of topographic mapping". The georeferencing challenge was overcome in 1983 when the American GPS service was made available to citizens. 
Arp et al. (1982) raised two important points relevant to the introduction of novel technology in general that resounds with the introduction of mobile LiDAR to underground mining.
"The profile interpretation may bring very valuable and detailed information about geomorphology and geographical features of usually unexplored and badly studied regions."
"It is recognised that later more precise maps may be needed for planning dams, powerhouse, transmission lines, roadways or canals."

To Arp et al.'s first point, although the technology and subsequent methods for visualising and interpreting the data had an initial intended purpose, there are previously unforeseen applications and advances. This is true for mobile scanning methods in underground mines, although the research was undertaken to address a question regarding convergence and instability, the applications and advances have far exceeded this. Mobile LiDAR in underground mines has extended to applications in geology, mining engineering, surveying, and ventilation disciplines.

On Arp et al.'s second point, the incentive for using an emerging technology and developing a technique was the need to rapidly collect data across a large area more efficiently than conventional techniques allowed. Data accuracy was sacrificed in preference for spatial coverage and acquisition efficiency. The results were sufficient for their purpose but would have been insufficient for requirements needing a higher accuracy. Mobile LiDAR in underground mines offers a solution for rapidly acquiring data from vast areas, including areas inaccessible by humans, at a sufficient accuracy for many applications. However, the data limitations need to be understood.

A final point of discussion arises regarding emerging and improving technology. Arp et al.'s solution for georeferencing involved creating a photomosaic from aerial photographs taken from a $35 \mathrm{~mm}$ camera every three seconds. These were positioned by creating a local grid system, triangulating the photo location, and overlaying them on the photomosaic. Had the project been three years later, GPS would have been available to simplify the process and most likely improve the accuracy. The point to raise here is that technology is continually advancing and tomorrow's solutions involve piecing together today's technology. The same can be applied to underground mobile mapping. The hardware has been created by robotics and mechatronics groups, the firmware has been developed for a generic requirement for localisation without GPS, the software was developed as a requirement for visualising large point cloud datasets and the alignment algorithm written for measuring the change in riverbed sediments.

Since the initial involvement in bringing mobile mapping to underground mining as early as 2002 (Nuchter et al. 2004) and their commercial availability in 2014, there have been significant technology advancements to create geomechanics solutions. The autonomous automotive industry has significantly advanced LiDAR sensor technology. Localisation methods have progressed, alignment algorithms have improved, and the understanding and interpretation of the results have advanced. The current use of mobile LiDAR for underground mining applications is really at the start of its journey. What was used in 2014 is now 'old', what is currently used was the 'future', and what was a concept is 'now just around the corner'.

The following sections in the paper aim to summarise why there was a need to bring mobile LiDAR to underground mining, and the motivations for pursuing this research. Its position amongst other monitoring and measuring instruments and sensors is summarised along with a discussion around the context of underground geomechanics observations. The paper then discusses the many underground geomechanics lessons learned since implementing mobile LiDAR and how the methods will continue to evolve. It is predicted that mobile LiDAR will form a pivotal role in the future of underground geomechanics and mining in general. 


\section{Why mobile LiDAR has real potential for underground geomechanics}

Conventional change detection instrumentation and sensors used for underground geomechanics monitoring are typically point-source or small-scale measurements. This may take the form of extensometers, strain gauges, distometers or survey prisms. In some circumstances, static scanners may extend coverage to a broader area such as critical infrastructure and intersections, but rarely would this technique be applied to vast areas of a mine. Access restrictions within underground mines make spatially continuous displacement data acquisition and monitoring exceptionally challenging. Coverage of an entire underground mine is either not undertaken or is done using damage mapping based on visual observations, whereby interpreted rock mass damage is recorded. This method is subjective, inaccurate, and largely qualitative. For quantitative, spatially continuous, mine-wide coverage, conventional monitoring techniques provide limited options. This gap is just one application where mobile LiDAR scanners have an important role.

The incentive to research a method to capture quantitative, spatially continuous, mine-wide monitoring data arose from a personal involvement with two exceptionally large seismic events. The first event occurred three days after commencing work as a geotechnical engineer. It provided a firsthand experience of the size and violent nature of rapid, brittle failure. As a new engineer, an intense learning period followed this experience. Over the following months, it become clear that such events are usually rare and that the engineering concepts presumed for the failure mechanism, loading conditions and ground support did not accurately reflect the aftermath observations. Very large seismic events are treated as rare events; defined as discrete, statistically improbable, and infrequently observed. So, if this were truly the case for large damaging seismic events, then it would be very unlikely to be exposed to a second similar event at a second, independent mine. Once, you are unlucky; twice might be coincidental; but when, as a young engineer, you start finding out that this 'rare' phenomenon is occurring far more often than published, you start questioning what other methods might help anticipate them.

The conditions leading up to the second event and its back analysis are discussed by Drover \& Villaescusa (2015). In hindsight, from this event and others reviewed subsequently, these large seismic events resulting from mine-scale rock mass instabilities do not occur without warning. The emerging instability precursors may not always be recognised as indicators, or they may be attributed to another cause, but one way or another, there are signs that the rock is becoming unstable. The specifics predicting when a large event occurs, such as how large it will be, where it will cause an impact and to what degree will, for the foreseeable future, continue to elude engineers. What might improve the large seismic event predictability to improve the identification of indicators and precursors.

The concept of identifying an emerging instability and forecasting an approximate failure time is routine in other geomechanics fields. Real-time, remote sensing methods were introduced to open cut mining with slope stability radar in the late-1990s (Reeves et al. 2001). The past twenty years has seen advancements and acceptance of radar monitoring techniques within the open pit mining industry. The techniques high sampling rate, density and accuracy have all aided in large-scale open pit instability identification well in advance of their final failure.

On 10 April 2013, the largest open pit slope failure in history occurred at Rio Tinto's Bingham Canyon mine, termed the Manefay landslide. This failure did not happen without warning; by the time it occurred the site was ready; personnel had cleared the it and equipment prepared for the failure. A detailed account of the event is discussed by Ross (2017). Nine months prior to the failure, in June 2012, smaller instability indicators and precursors above the Manefay fault had been observed. These small-scale instabilities alerted the geotechnical engineers that additional monitoring was required. Persistent small movements were measured in proximity to the June 2012 site. In January 2013, prisms detected movement of a separate block lower on the pit wall. Again, additional monitoring was installed, and the pit inspection frequency increased. Ross described that by February 2013, it became apparent that the highwall would probably fail and the site shifted to managing the emerging instability and preparing the site. Although the monitoring data identified that a failure would occur, the timing, size, and impacts could not be accurately predicted. For the Manefay 
landslide and open pit failures in general, remote sensing played a pivotal role in the early detection and the ongoing instability monitoring and emerging hazard management.

The Manefay landslide observations described by Ross have similarities to those experienced in the event described by Drover \& Villaescusa (2015). Prior to the eventual failure, the rate of seismicity and frequency of large-magnitude events increased, as did observable ground support loading and damage to surface support within the excavation. Based on subsequent experience in similar scenarios using mobile LiDAR monitoring, convergence within the drive would have been detected.

As with the open pit example, the concept of multiple indicators leading to larger precursors, damage and eventually failure is well documented. The concept of systematic changes is fundamental to the observation method (Peck 1969) and the Rock engineering matrix (Jiao \& Hudson 1995). Past underground mining failures are reviewed by Szwedzicki $(2001,2003)$, identifying that precursors are often documented prior to an eventual failure. Szwedzicki (2003) produced a sequence of precursory rock mass behaviour prior to regional failure (Figure 1). These observations provide qualitative rock mass observations to be considered, not as discrete events, but potentially belonging to a larger instability that manifests with respect to time (Figure 2).

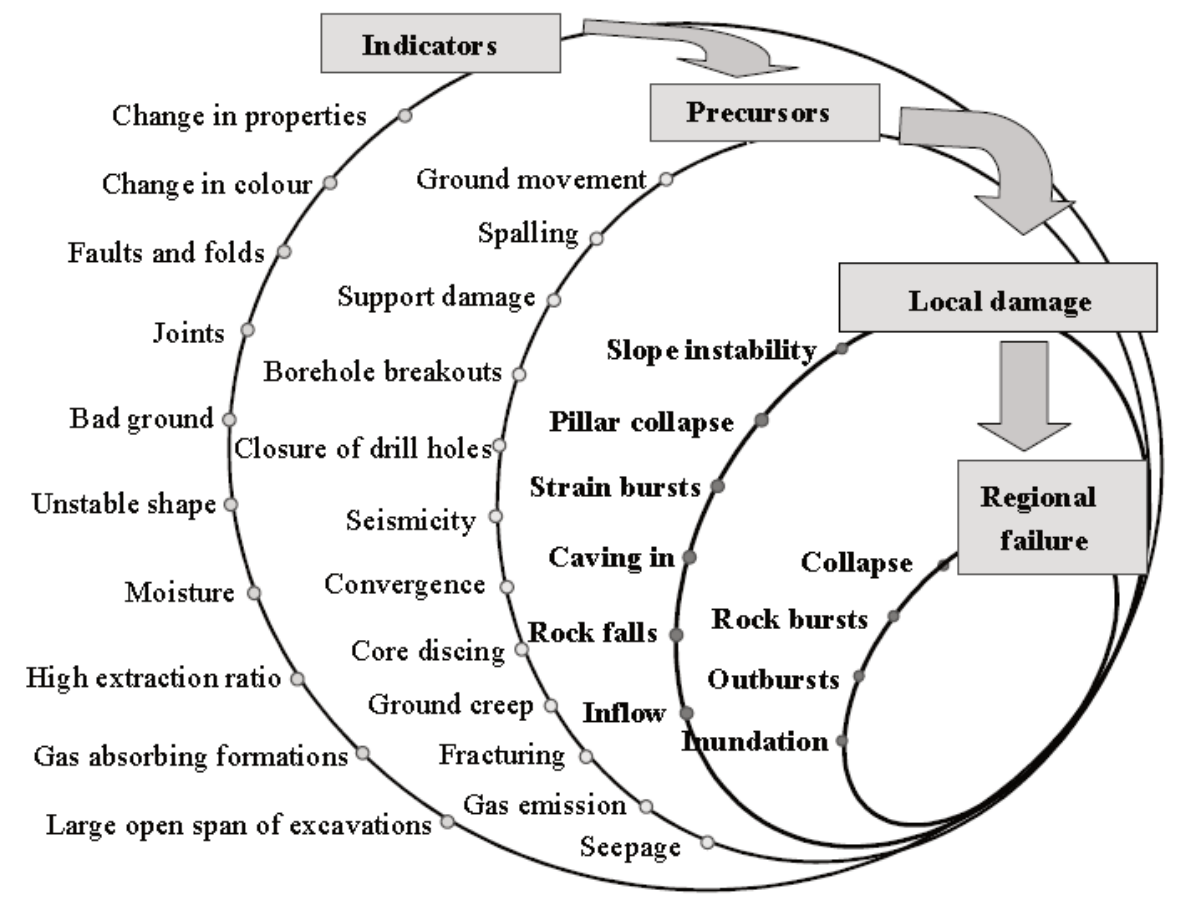

Figure 1 A sequence of rock mass behaviour leading to regional failure (after Szwedzicki 2003) 


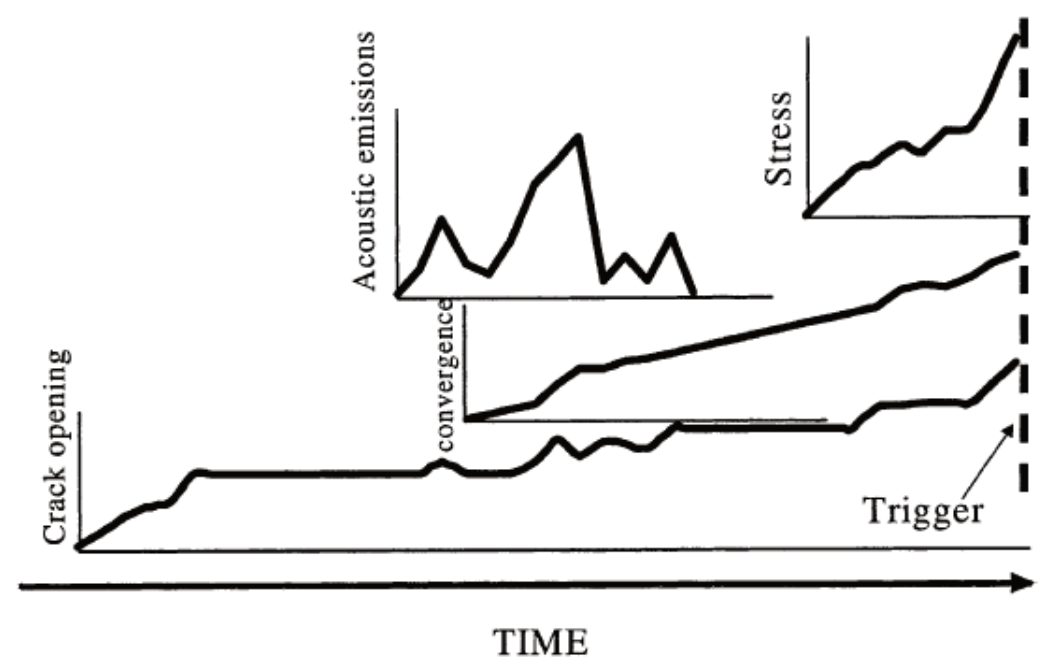

Figure 2 Manifestations of multiple rock mass observations prior to failure (after Szwedzicki 2003)

Szwedzicki (2003) highlights geotechnical instrumentation and monitoring's importance, contending that large-scale failures are neither random nor without warning. Notwithstanding that this may be obvious in concept, it appears that this is not always accepted or implementable in practice. So, why is this?

Why is it that in the slope stability example, the time, scale, and impact of an eventual large-scale failure was identified and predicted, whereas underground large-scale failures are often portrayed as unpredictable?

A large part of this answer comes down to how our brain mentally and computationally processes observations and data, particularly with increasing data uncertainty. The process of forming judgements, decisions and finding solutions to complex datasets using simple mental strategies is known as a heuristic. This field of psychology is has gained traction in understanding decision-making processes following the paper Judgement under uncertainty: heuristics and biases (Tversky \& Kahneman 1974). Leading on from heuristics are a range of decision-making theories, in which the Cognitive Miser Theory is one. This theory works on the basis that the human mind reduces its cognitive effort by simplifying problem solving methods. Where heuristics, biases, and cognitive effort play a part in geomechanics as data becomes increasingly sparse, from seemingly independent sources and discrete in nature, a greater cognitive effort is required to recall and identify their connectedness. If your mind is unable to easily connect information, then forming these relationships takes effort and relationships are missed. This is where remote sensing data play a large part in instability recognition.

In the case of open pits, the data are sampled at a sufficient density that resulting picture is effectively spatially continuous, and the sampling frequency means that time-dependent trends are easily recognisable. The dataset presents a continuous picture in four-dimensional space-time. An underlying issue with just about all data from underground is the lack of spatial continuity. The low sampling frequency often means that the measured data fail to capture the actual rock mass behaviour. Given these limitations, it is often difficult to construct the spatial relationships required to identify emerging trends between multiple discrete observations at the multiple length scales and time periods. Furthermore, the qualitative nature of broad coverage damage mapping means it is difficult to track failure modes that manifest over a period of months. The importance of broad coverage, spatially continuous, quantitative data cannot be understated for identifying emerging instability trends.

Commonly observed underground rock mass instabilities are displayed in Figure 3 with respect to scale-dependency and rate of change. Examples of conventional instrumentation used for identifying and monitoring these failures modes is presented on the same scale in Figure 4. The gap in quantitative data coverage over long durations and large-length scales becomes apparent and highlights the importance of mobile LiDAR as a monitoring technique for underground geomechanics. 


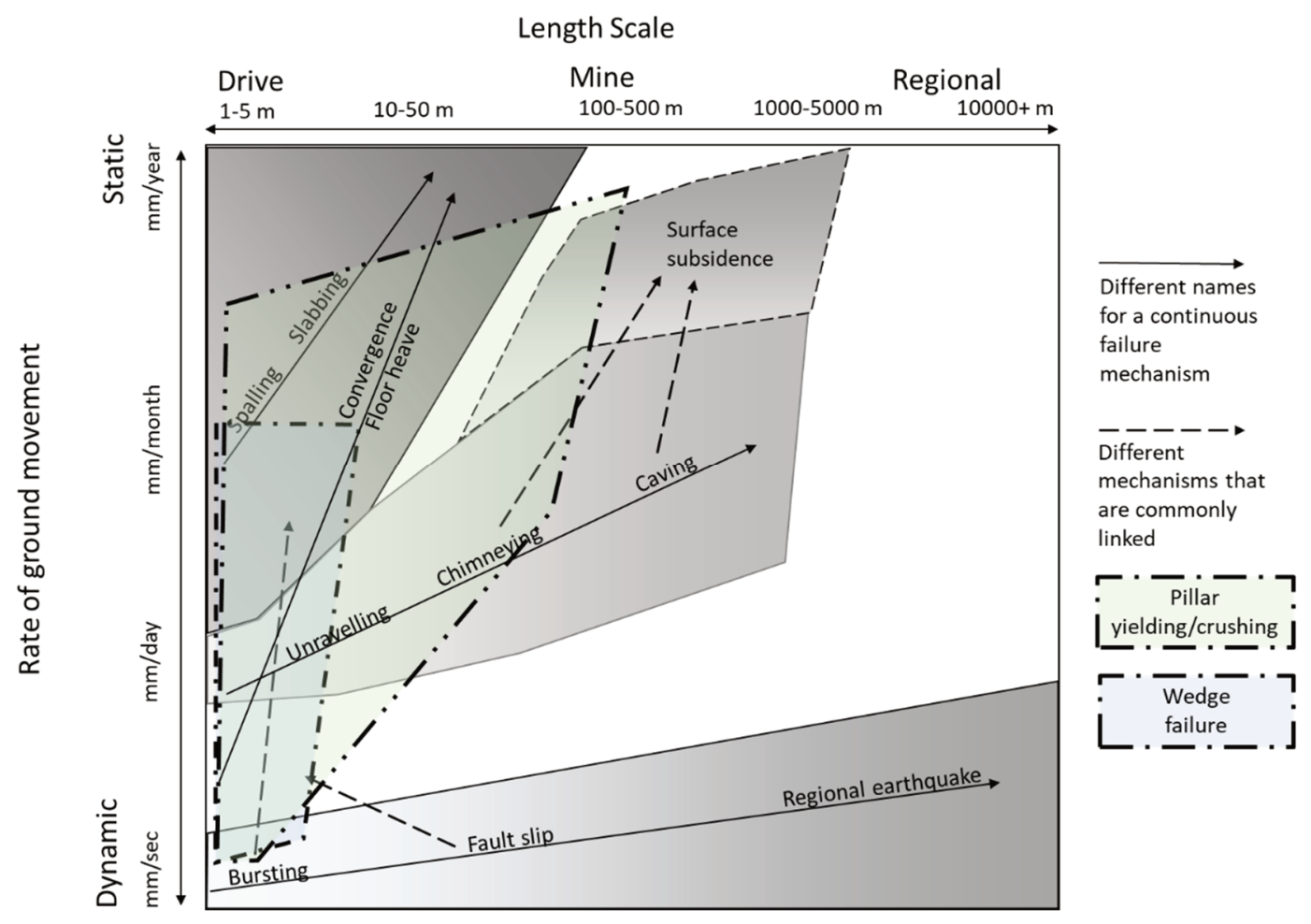

Figure 3 A range of rock mass failure modes commonly observed in underground mines showing their manifestation and scale-dependency

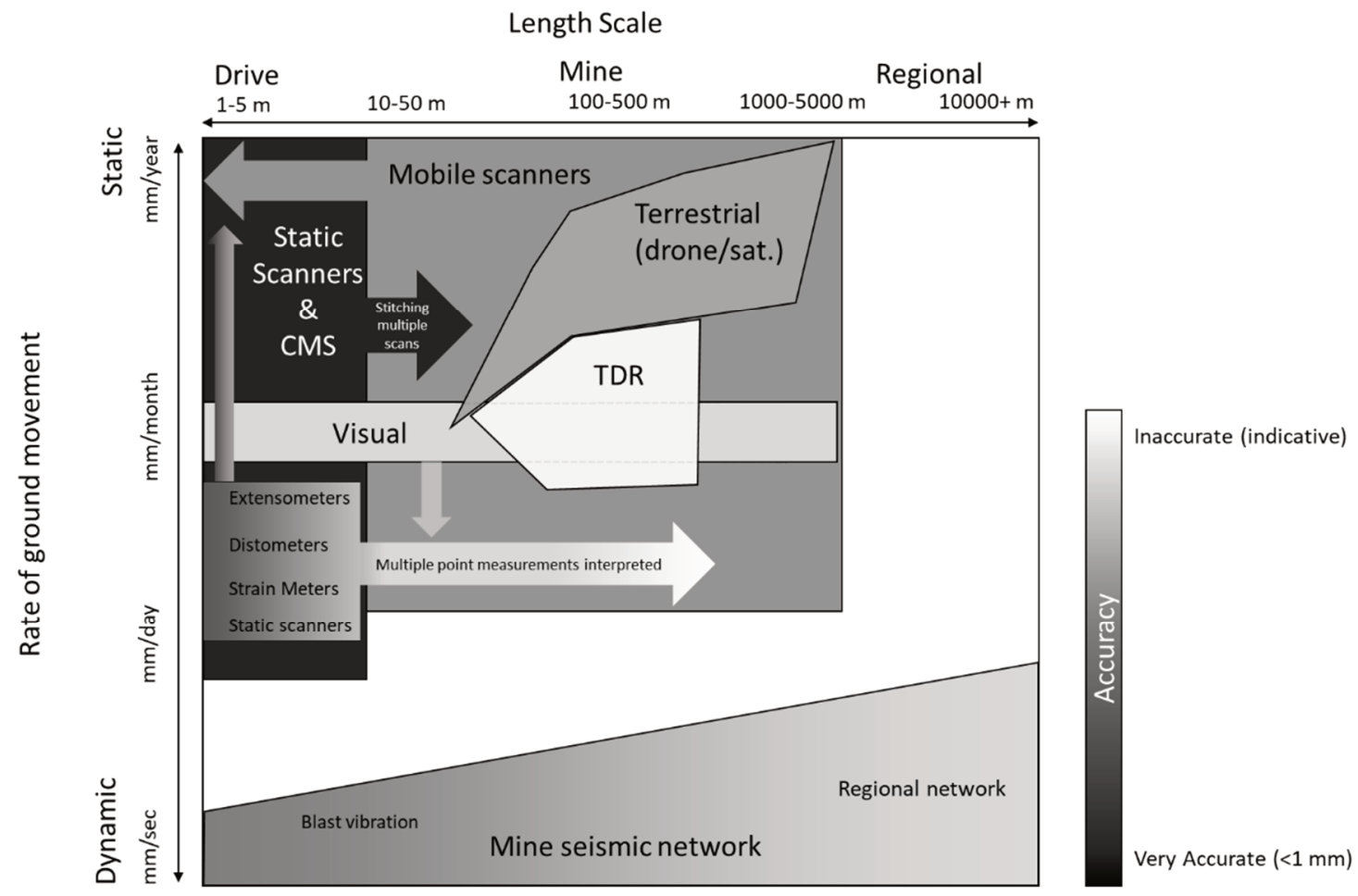

Figure 4 The array of instrumentation applied to underground geomechanics showing the applicability to the monitoring length scale and rates of movement they can be applied to. Colour scale is approximate accuracy of the monitoring method 


\section{Learnings from the twenty-teens}

LiDAR has seen rapid growth over the past decade in a wide range of industries. It is entering its golden era as multiple technology fronts converge, pushed strongly by industries chasing remotely sensed spatial data for applications such as transport, agriculture, and town planning. The GPS-denied mobile mapping sector was largely created through the commercialisation of the Zebedee laser scanner (Zlot \& Bosse 2012) (Figure 5).

In reflection, development over the past six years can be summarised:

- Hardware familiarisation.

- Data and software familiarisation.

- Development of workflows and analytics.

- Integration into operational underground mines sites.

Highlights of these aspects follow.

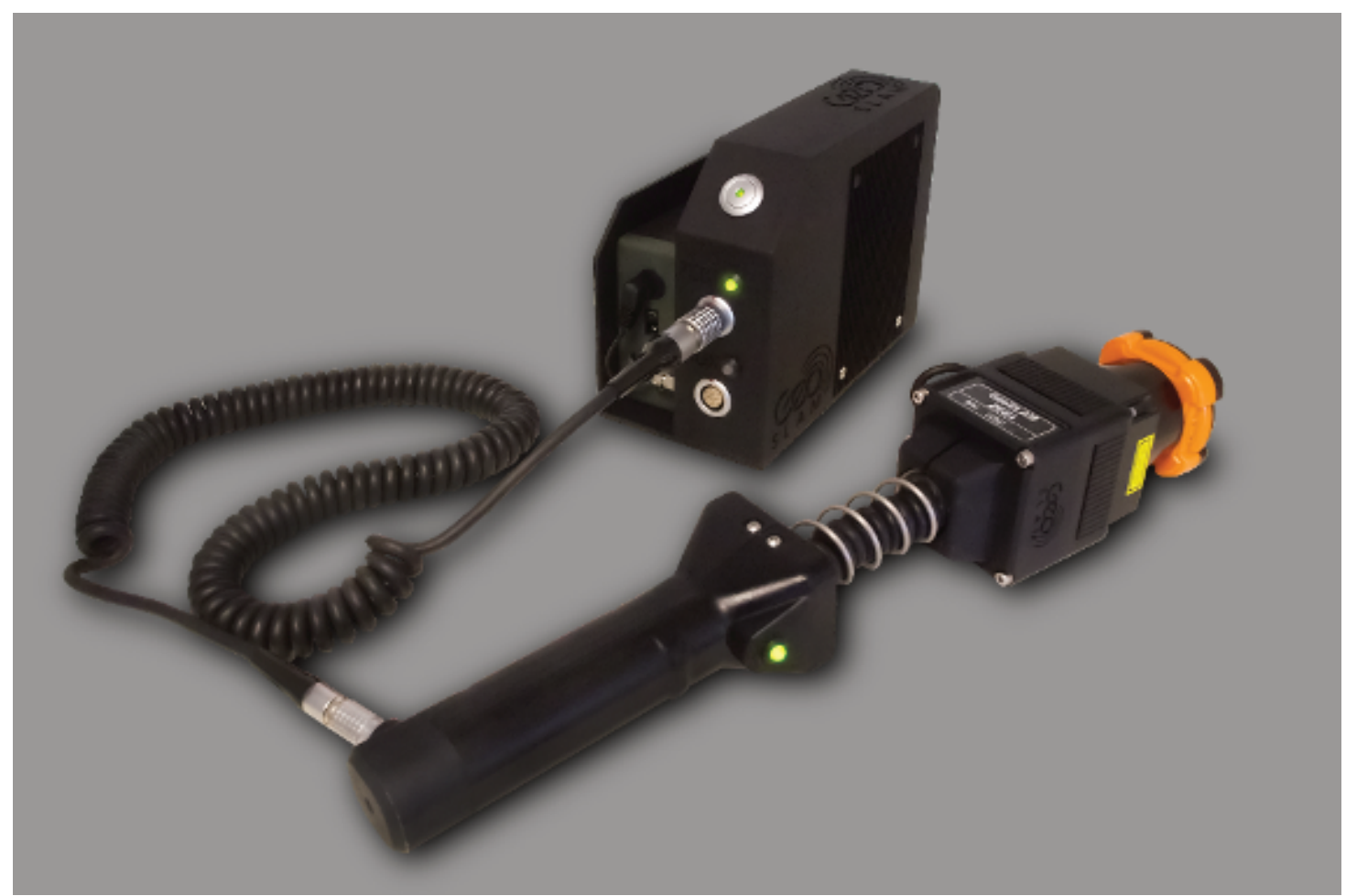

Figure 5 An image of the original GeoSLAM Zeb-1 Mobile scanner developed by CSIRO (Duff 2016)

\subsection{Mobile LiDAR hardware and data acquisition}

Mobile LiDAR hardware includes a range of devices and platforms that creates a point cloud of the scanned environment while moving. A LiDAR sensor/s suitable for the application is coupled with a form of movement recognition device or sensor, which could use GPS/Global Navigation Satellite System (GNSS), an inertial measurement unit (IMU), a radio frequency beacon, stereo-cameras, or a combination of sensors. There are three main issues relating to hardware and firmware for use in underground mines. The first is the mechanism whereby a sensor with a two-dimensional planar field of view is adapted to a three-dimensional spherical field. The second is the localisation method in a GPS-denied underground mine. The third involves the rapid evolution of LiDAR sensor technology.

The mechanism that takes a planar field of view and creates a spherical field of view is important. In the initial Zeb-1 device this mechanism required manual user input, nodding the LiDAR sensor back-and-forth on a 
spring. The resulting data point distribution was very irregular with high point densities located at the full tilt backward and forward when the sensor is effectively stationary. In many commercially available devices since 2015 , the mechanical rotation has been a continuous $360^{\circ}$ rotation on an axis orthogonal to the LiDAR spinning axis. This change in rotation mechanism provides an almost even point density. The differences between the two mechanisms are shown in Figure 6. The same LiDAR sensor is used for both images; only the nodding mechanism versus the mechanical rotation is changed. The implications of this advance were profound. No longer was the operator required to ensure a full range of motion that had to be nodded at just the right frequency. The results were sensitive to incorrect nodding frequency and this would occasionally introduce errors into the dataset. Nodding and walking on uneven ground was a coordination test, often resulting in their attention and not focussing on where they are walking. Another advantage arising from an even point cloud density was improved object definition leading to better overall scan accuracy. The simultaneous localisation and mapping (SLAM) algorithms that are used for localisation work on the basis of object detection and triangulation, based on prior scanned objects (Figure 7). As there is no requirement for absolute global positioning, the resulting point cloud is not georeferenced. This is evident in the figure showing the offset between the 'estimated' and 'true' pathways and landmarks (objects). The improved object definition provides more landmarks for triangulation, improving the final scan accuracy.

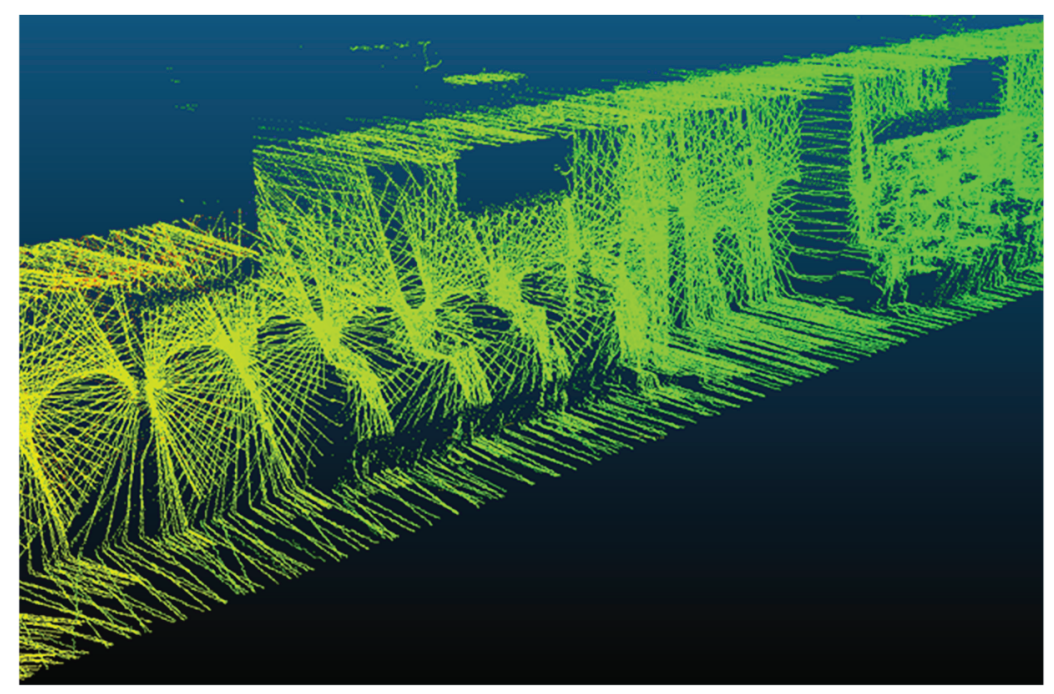

(a)

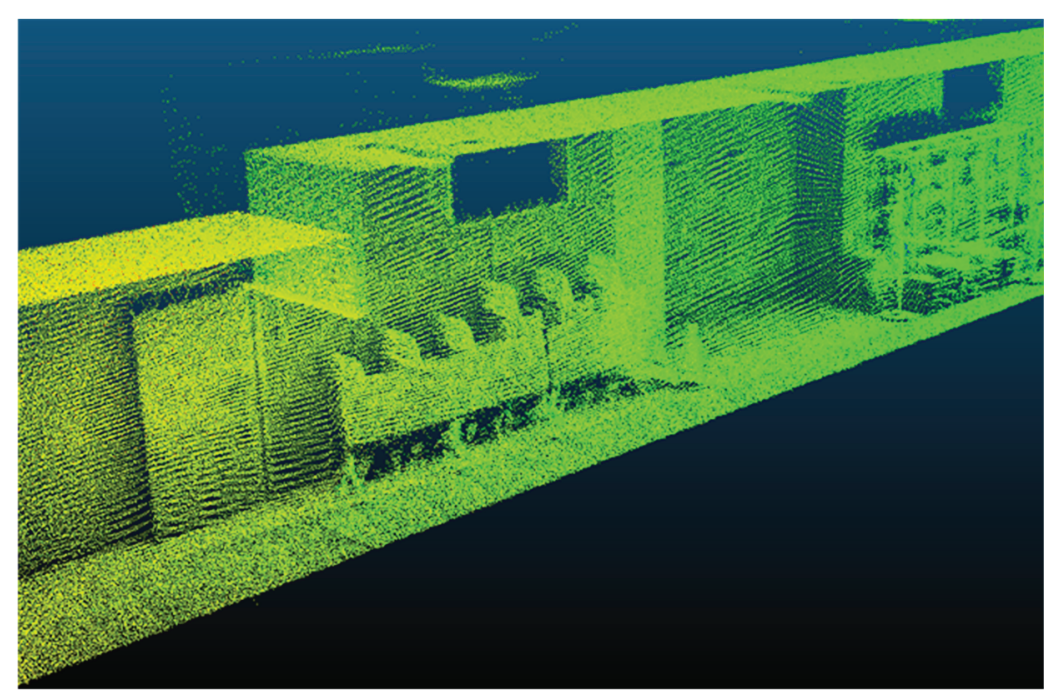

(b)

Figure 6 A section of a point cloud through a corridor scanned using two different rotation methods. (a) Image uses a manual nodding mechanism; (b) Image uses a mechanical rotation 


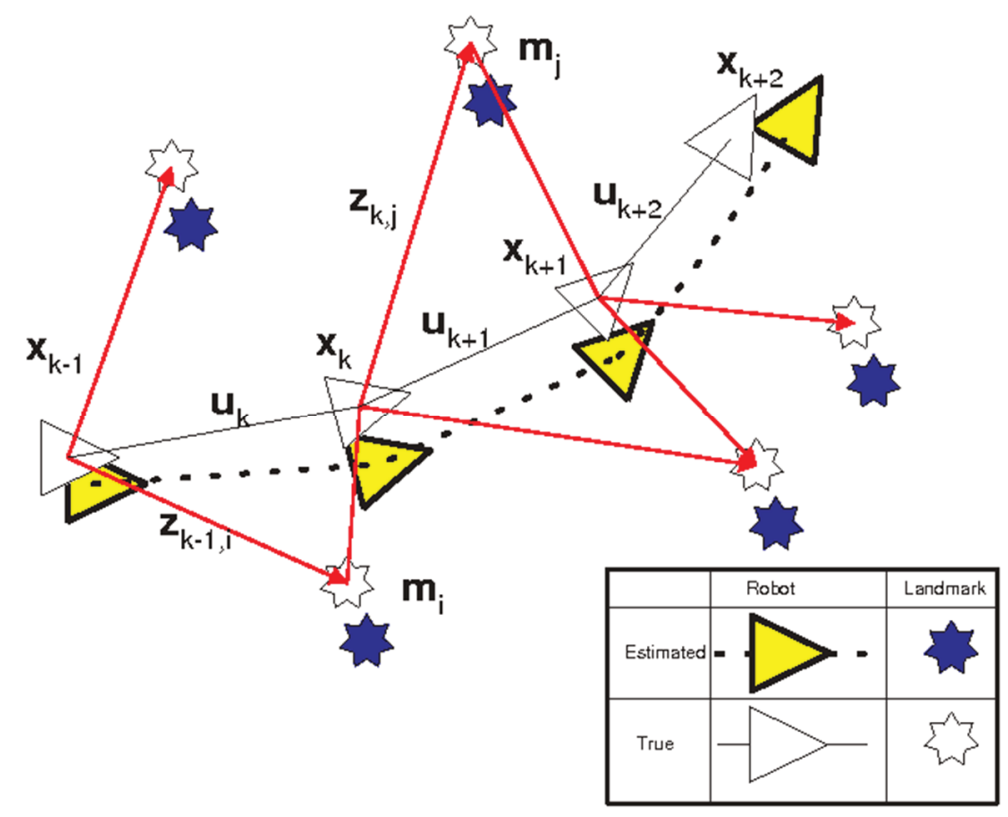

Figure 7 The essential simultaneous localisation and mapping (SLAM) problem. A simultaneous estimate of both robot and landmark locations is required. The true locations are never known or measured directly. Observations are made between true robot and landmark locations (from Durrant-Whyte \& Bailey 2006)

The two localisation methods in GPS-denied environments that have shown the most promise involved SLAM algorithms (Durrant-Whyte \& Bailey 2006; Bosse \& Zlot 2009) and the occupancy grid method (Artan et al. 2011). The localisation methods are, in essence, the brains behind the eye, imposing order on the millions of LiDAR returns, transforming them into a spatial array replicating the scanned environment. From the device operator's perspective, it is not imperative to understand the coding behind these algorithms. However, understanding the algorithm concepts and limitations will help recognise when the algorithms have failed. Useful limitations to appreciate include:

- Does the algorithm require global loop closure? Are internal loops recognised and impact the final solution?

- What are the maximum and minimum operating speeds?

- How are they impacted by a rapid scene change? I.e. moving through a doorway where there is minimal prior knowledge for new data to be located.

- What size features are required for localisation?

- Can additional sensors be incorporated to improve accuracy (RFID, GPS/GNSS, optical)?

Over the past six years, the localisation algorithms have improved immensely and will continue to do so. The results are erroneous less often, they are less sensitive to variations in inputs, and new inputs (RFID, GPD/GNSS, internal loop closure, etc.) are becoming available. Although there is less dependency on the operator to understand how they work, knowing so is both intriguing and valuable for generating consistent data. It follows that the time and effort invested in becoming familiar with LiDAR fundamentals is worthwhile. For many geotechnical and mining engineers, current exposure to LiDAR will have been limited as LiDAR is relatively new to these professions. There are several major brands with various sensor types but for the consumer devices being applied to mobile mapping in mining at the time of writing, three dominate the market:

1. Hokuyo UTM-30LX.

2. SICK LMS111.

3. Velodyne VLP-16. 
A LiDAR sensor's range, sampling rate and ability to assign attributes to each point are some factors that affect the overall scan quality and accuracy in mobile, SLAM-based point cloud results. Sensor range affects the maximum distance the device can scan. Both the Hokuyo and SICK sensors have a $\sim 30 \mathrm{~m}$ maximum range, while the Velodyne's increases this to $\sim 100 \mathrm{~m}$. Although $30 \mathrm{~m}$ is suitable for many geomechanics applications, the Velodyne's additional range has two main benefits. For applications such as scanning within large stopes, the range provides coverage at a greater distance. This additional range also enables feature recognition at greater distances for the SLAM algorithm. In the context of SLAM algorithms, development in underground mines is feature poor. Features used for underground localisation are often variations in drive profile (i.e. intersections, turnouts and drawpoints, etc.) and infrastructure objects (i.e. vent fans and bollards). These features often exceed 20-30 m intervals, meaning the sensor is feature deprived for some part, reducing the localisation effectiveness which, in turn, can introduce error. With the additional range, these features are identified and used at a greater distance improving the scan's global accuracy, reducing data-drift (the banana shape) within long scans (Figure 8).

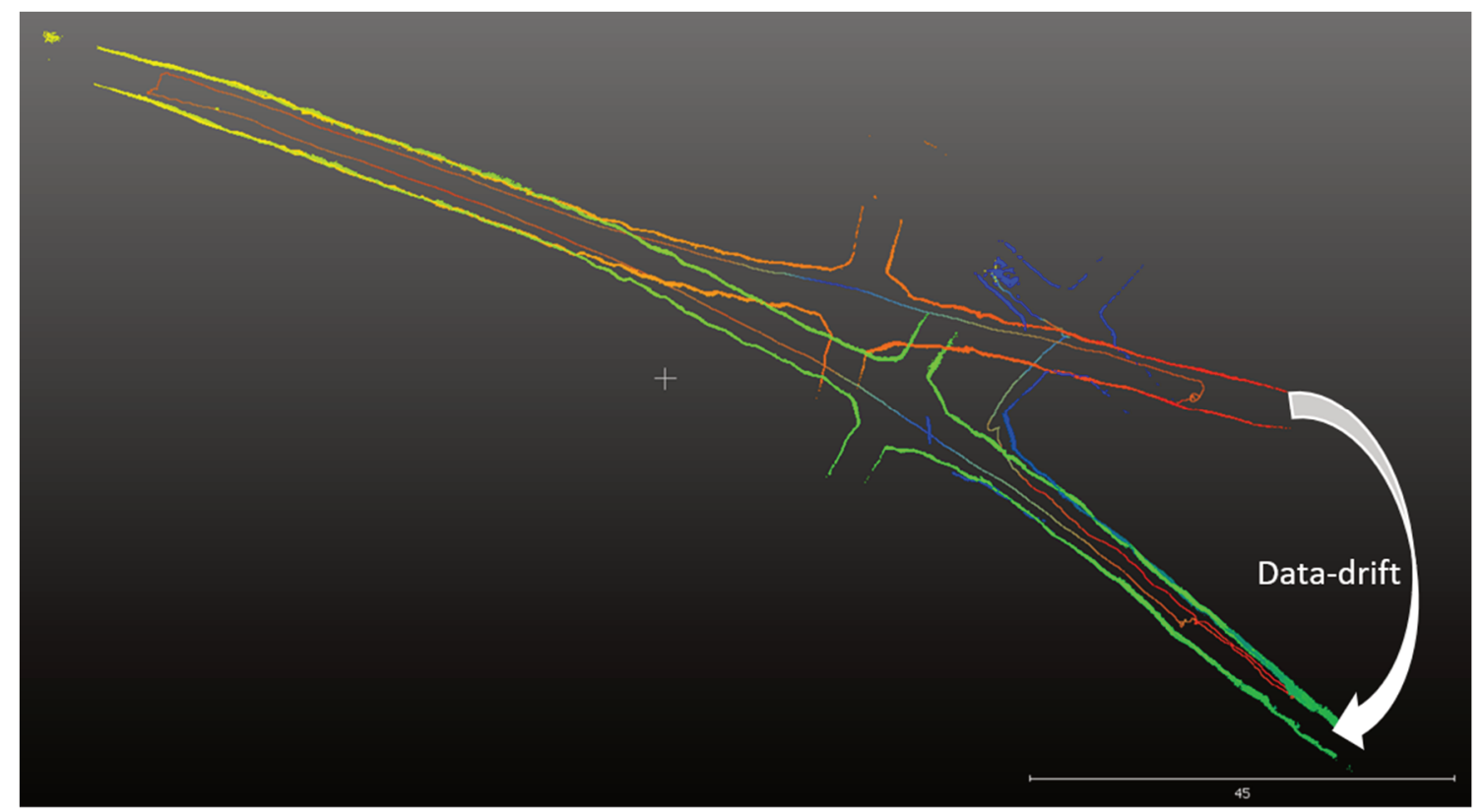

Figure 8 An example of inertial measurement unit (IMU) drift within a scan. This error was not uncommon with devices with a short range (20-30 m) and issues with the device operation in feature poor environments

Sampling rate is an important factor for similar reasons as point cloud density, being object clarity for SLAM recognition and results interpretation. The Hokuyo and SICK sensors are single beam, planar scanners with a maximum sampling rate of $\sim 43,000$ points per second (pps). This sampling rate was typically sufficient, helped in part by the limited range and slower scanning pace as most scans were conducted while walking or driving slowly. The Velodyne VLP-16 increases sampling rate to 300,000 pps by simultaneously scanning 16 rings providing a $30^{\circ}$ vertical field of view. This increased sampling rate is necessary to create a sufficient point density at maximum range for object detection. This sampling rate far exceeds the requirements for mapping development but for mapping stopes, it reduces the required flight time of drones that are limited by battery duration and exposure to falling objects.

Attributes such as the return intensity (object reflectance) and range are both valuable for filtering data and providing context to the scan.

There are drawbacks associated with the VLP-16 including:

- An increase in weight. If scanning by hand or mounted to drone, the increase in weight has implications on the ergonomics and battery duration, respectively.

- An increase in cost. 
- Longer processing time. The increase in data points requires longer processing. This duration depends on the localisation method. Processing time is improving as methods become more efficient and processing power increases.

- Larger datasets. Very rarely will an entire dataset be used, even for the lower scanning rates. The required data density is a function of the application. Higher point density does not always mean greater accuracy or precision.

The topic of data accuracy has largely been avoided in this paper as there is no simply definition and it requires a detailed discussion. Jones et al. (2018) provided a study on the factors influencing accuracy and a method for measuring it. As new LiDAR sensors and SLAM algorithms are developed, both will continue to improve the accuracy and precision of the point clouds used for underground geomechanics. To understand a device's limitation, it is an important to understand accuracy, but given the array of factors impacting accuracy, it is best not to report this as a generalised number. The important lesson is that, for many applications, the accuracy and precision of the data acquired is sufficient to improve upon existing methodologies. This is not to say it is currently perfect (it is not) but it will continue to improve. There can be an over-emphasis on accuracy requirements, and for some applications, high accuracy and precision are required. For these, mobile LiDAR may simply not be the correct hardware or monitoring method. In determining what is required the following should be considered:

1. What is the current methodology and accuracy being used?

2. Is accuracy lost in the reporting and storage of the data?

3. Would mobile LiDAR improve upon the accuracy for the same task?

4. Do point clouds create a more accurate record of the data?

Sensor technology has evolved and will continue to do so. The sensors used, and the improvements to them, are largely being driven by industries external to mining. The automotive and aerial scanning sectors are the main drivers behind LiDAR innovation, with the mining sector being a beneficiary. It is important to note that data acquisition is not currently the bottleneck for LiDAR to become a mainstream underground geomechanics monitoring method (for most applications). For purposes where accuracy is paramount, there are other commercially available solutions. A factor holding the industry back, is the expectation of terrestrial scanner accuracies and coverage in underground environments as out-of-the-box solutions. To reach this point, the industry needs to adopt and learn the current technology and provide feedback, funding, and access to original equipment manufacturers (OEM) developing the next generation of mobile scanning hardware. The second requirement is for the industry to learn how to use the data and partner with companies developing the software, interface and analytics that ultimately provide the insights from the data.

\subsection{LiDAR data and software}

From experience, transitioning to using point clouds has been challenging. This challenge exists at multiple levels, but great benefits exist for underground geomechanics applications. Each return is a single data point to which attributes are assigned. These attributes provide information beyond simply a location in space. A group of points create a surface, a shape, its roughness, and curvature. A cross-section provides a detailed perspective a drive's profile. The scan of an entire drive provides geometric variability, while each drive when georeferenced provides 3D spatial context. Herein lies one of the largest challenges; a $5.5 \times 5.5 \mathrm{~m}$ drive with a $25 \mathrm{~mm}$ spacing between points is approximately 15,000 points/linear metre. Visualising an entire mine, even a small operation, will exceed many software visualisation package's rendering capability, especially if it is optimised for triangulations (wireframe and solids) as many mining packages are.

The software requirements for manipulating point clouds depends on how the dataset is to be used. For high-resolution, small-scale computations such as convergence monitoring, a high-density point cloud is required. The software must manage hundreds-of-millions of points, excluding most triangulation-based visualisers. Over the past few years, there has been a shift in closing the gap between conventional mining 
software and that which analyses point clouds. Although the gap is closing, there remains a distinct trade-off between the functionality and tools available in point cloud software, and the inter-operability with mining packages. There are distinct advantages of working with high-density, information-rich point clouds, but there is an understandable preference to work with familiar mining-specific software. This, in turn, creates an additional workflow step at the interface between the new and the familiar.

\subsection{Point cloud workflows and analytics}

Working with point clouds for underground geomechanics applications remains a very hands-on process. It is by no means a one-button, automated 'here's the answer' process. However, this is changing and processes such as filtering, georeferencing, alignment, and change detection are becoming available within some packages. Just as it is important to understand the nuances in the functionality of hardware, it is equally important to understand how an automated process works and what the results are showing.

On multiple occasions, the 'how' and 'what' of using point clouds for geomechanics applications have been a source of erroneous applications, an example being convergence monitoring. The process for change detection (convergence monitoring is an interpretation of change detection) involves the following steps:

1. Conduct an initial baseline scan of the excavation.

2. Later, scan the area of interest a second time.

3. Align the two scans.

4. Compute the difference between the two scans.

5. Visualise the results.

This 'simple' example is discussed at length by Jones \& Beck (2017) and Jones et al. (2018), whereby various methods to complete steps 3 and 4 are highlighted as sources for error and producing varying outcomes based on the methods applied. For underground excavations, movement direction and orientation is particularly relevant. Movement into the void (i.e. a reduction in the excavation cross sectional area) is associated with convergence. An increase in the excavation cross-sectional area, or widening, is attributed to divergence (a loss of material). In the Figure 9 example, a decrease in $x$-direction of the right wall indicates convergence but would theoretically have the opposite interpretation to a decrease (divergence) in $x$-direction of the left wall. For this reason, the change detection algorithm must determine both magnitude and direction relative to the centre of the drive. Displaying magnitude of change, rather than distinguishing magnitude and orientation, produces a vastly different interpretation.

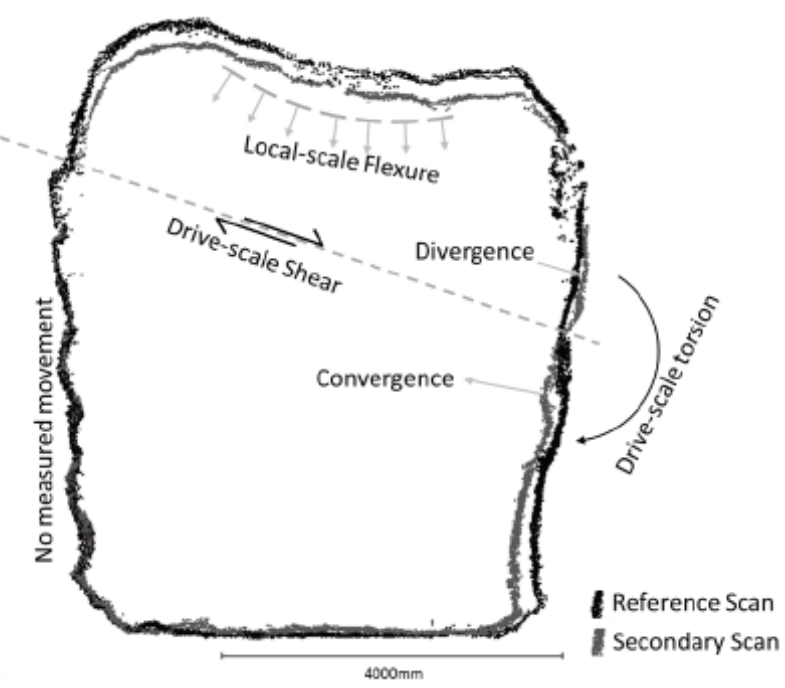

Figure 9 Multiple length scales and mechanisms of deformation shown in a single cross-section of a LiDAR scan within a deforming excavation (Jones \& Hancock 2019) 
In earlier sections, it was discussed how small changes may be attributed to an emerging larger mechanism; that the observations are a symptom, not the causation. Although there are insights garnered from using point cloud results in isolation, the real benefit becomes apparent with the inclusion of other contributing factors and independent observations. For instance, change detection along a single excavation may identify areas requiring inspection, but this is a local outcome. Coming back to heuristics, the extension from one to many excavations provides spatial correlations and common trends. Including lithology and structure (Figure 10) starts to provide context for the causation. Including other driving factors, such as voids and blasting, along with independent observations, measurements and forecasts (seismicity, stress cells, damage/rehabilitation mapping, stress modelling, etc.) all provide additional rock mass system insights and its response.

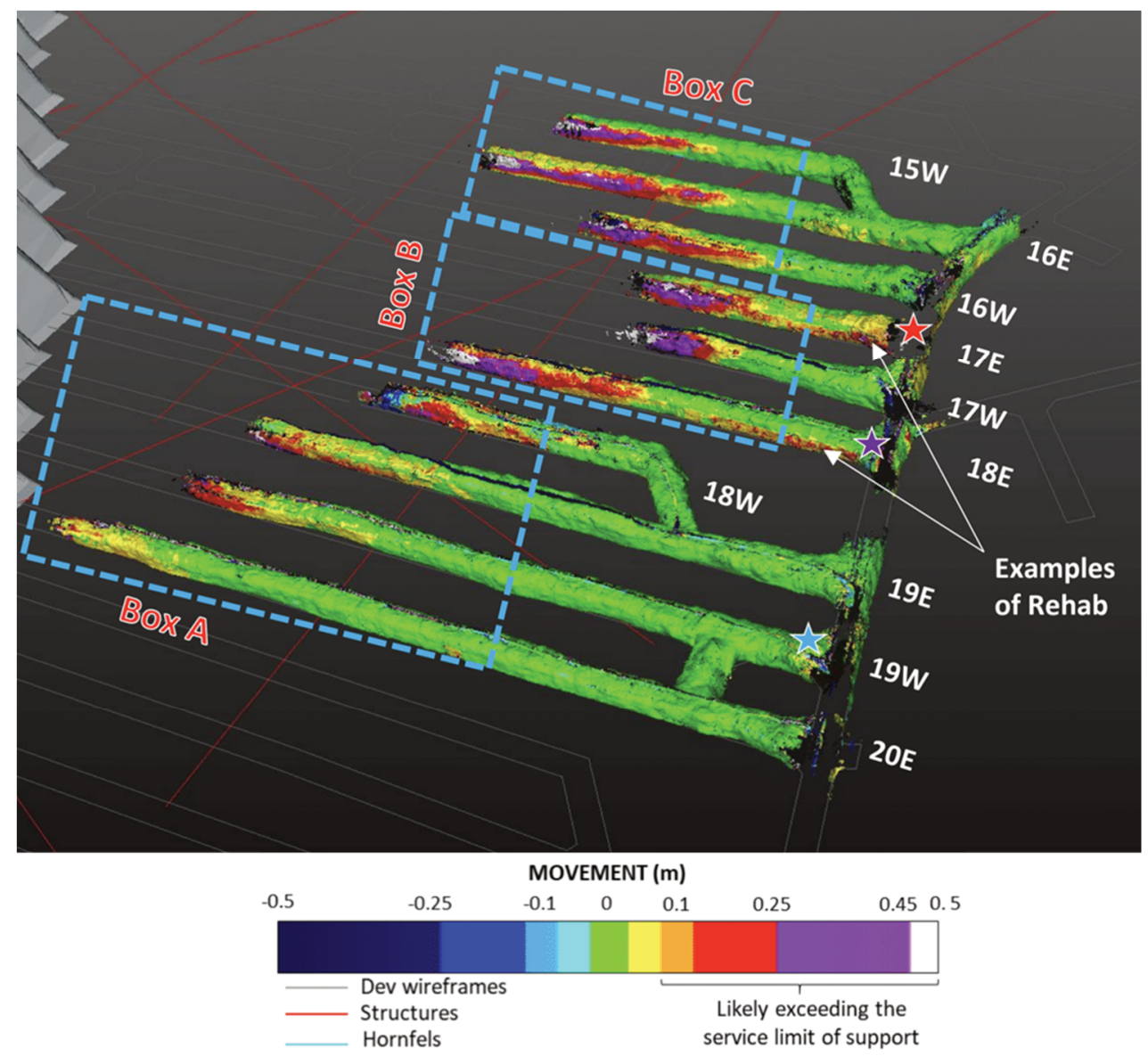

Figure 10 Example of combining multiple georeferenced scans, measured convergence, lithology wireframes, structural interpretations, and mining void. The combination of data provides greater context for the mechanisms causing the changes observed (Beck Engineering, pers. comm. 2020)

Just as remote sensing methods aided in the Manefay landslide recognition and management, its use is on the pathway to becoming a similarly important monitoring technique for underground mines. Whereas terrestrial monitoring is nearly an automated process, the equivalent workflows and analytics in underground applications are in their infancy. This hands-on, time-consuming process remains a challenge for the technique's mainstream uptake in mining operations.

\subsection{Integrating mobile scanning into operational mines}

With remote sensing techniques prevalent in other fields of geomechanics, one would have thought the uptake for mobile LiDAR scanning in underground operations would have been more rapid than it has been. 
New technology adoption is often described using Roger's adoption curve (Rogers 1962) to explain its uptake and popularity. The concept states there are five stages of adoption (Figure 11), these are:

- Innovators.

- Early adopters.

- Early majority.

- Late majority.

- Laggards.

As an estimate, the uptake of the technology for geomechanics purposes would, at best, be partially through the early adopters phase. It has been over a decade since the earliest research devices were trialled. With the advent of new technologies, improved workflow efficiencies and accuracy, there continues to be an acceleration in adoption.

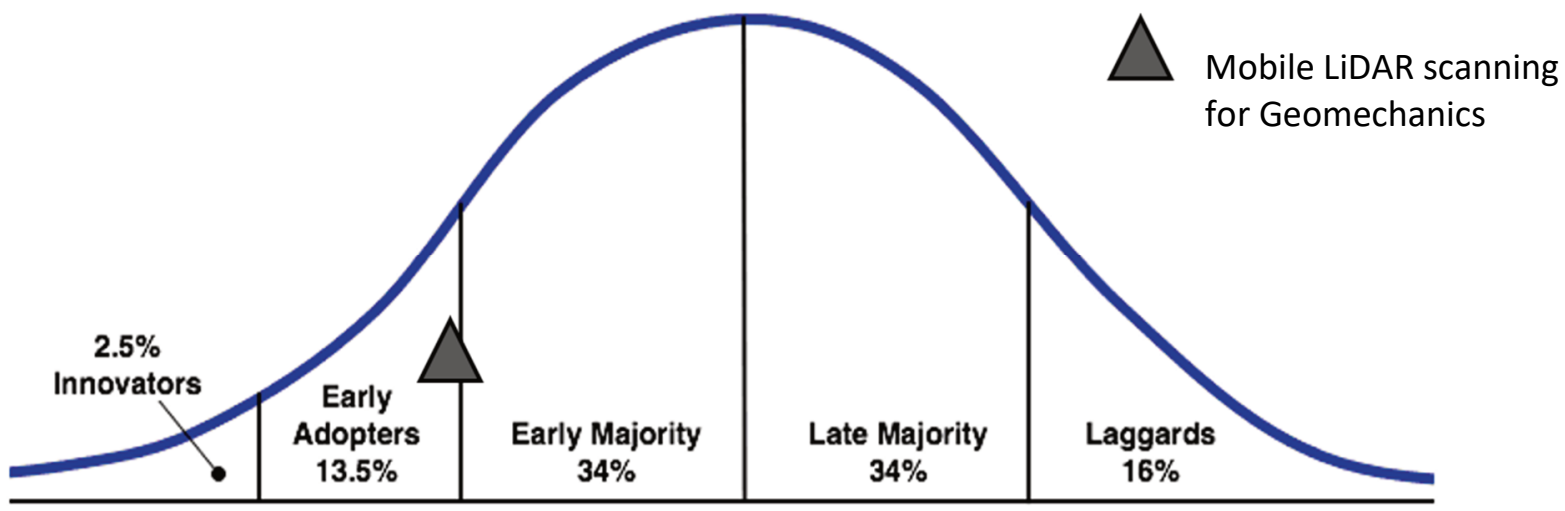

Figure 11 Technology adoption curve (Rogers 1962)

For a method that has seemingly obvious potential, this uptake appears quite slow. Why this is so, comes down to more than just hardware and software. The adoption by a mine site requires:

- The investment in new technology: mining companies and departments tend to invest in proven technologies, rather than the developers. Few sites want to be the 'early adopter'.

- Working with point clouds is foreign to most geotechnical engineers: point clouds have long been the realm of surveyors, but to fully adopt their use in geomechanics requires retraining, upskilling, and devotion by the individuals and the company. Sites are already stretched, so often there are insufficient resources to be applied to bringing the new technology into the department.

- Partnering with subject matter experts for training on using the hardware and introducing the new workflows: on multiple occasions, there have been sites that have purchased devices, acquired data but not produced what was expected. Seeking an external subject matter expert may have solved the issue or levelled expectations, but instead the technology has been shelved as the solution was not developed inhouse.

- The correct applications for the current limitations: mobile LiDAR has great promise for underground geomechanics applications, but it is not a single source for all data acquisition. The limitations may not be understood to the full extent leading to disappointment, and disappointment hinders early adoption.

Until early-2019, mobile LiDAR scanners were limited to areas accessible by foot or person-operated vehicles. The introduction of longer-range scanners mounted on drones has opened a broader range of applications within inaccessible areas (stopes and hazard zones), and mine sites, that can justify the use of mobile LiDAR scanners for geomechanics applications. 


\section{Current state and the future of mobile LiDAR for underground geomechanics}

Mobile LiDAR for geomechanics is currently only used at a minority of underground mine sites. The diversity of geomechanics applications and the efficiencies for resolving meaningful results continues to improve. Although improvements are taking place along the entire workflow from acquisition to application, it is in the initial data acquisition phase that progress is most evident. The reason for this, and the reason it will remain this way for the foreseeable future, is that underground mining applications are repurposing hardware created primarily for autonomous vehicles and aerial LiDAR applications. This is where the biggest markets are and where the funding for research and development is.

Autonomous vehicle used in underground environments received a boost in interest when the Defence Advanced Research Projects Agency (DARPA) announced the Subterranean (SubT) Challenge: a three-year competition running between 2018 to 2021. The competition's purpose is to "seek novel approaches to rapidly map, navigate, and search underground environments during time-sensitive combat operations or disaster response scenarios" (DARPA 2020). From this competition alone, the mining industry has started seeing the flow-on of new hardware, firmware, and information-rich data. It is now up to mining industry and geomechanical engineers to work with these OEMs to develop specific applications for these data.

\subsection{Hardware and firmware}

Many commercially available mobile LiDAR mapping systems available at the time of writing have not had an upgrade in sensor technology for 12 months. At this point of the adoption curve, the sensor technology exceeds the applications. The recent advances to come to market, and into mining, have been advances in:

- Drone autonomy in GPS-denied environments.

- Coupling with additional sensors such as cameras.

- Improved user interfaces.

- Improvements in SLAM.

The coupling of mobile LiDAR with autonomous drones has been a significant advancement for underground geomechanics (Vallejos 2019; Jones et al. 2019a, 2019b). This enables the acquisition of data within areas unsafe for personnel to travel, and to scan areas beyond the capabilities of remote, ground-based vehicles (tele-remote loaders and robots). A flow-on from the DARPA SubT challenge has been the rapid development in drone autonomy, waypoint placement and data streaming through the pilot interface. From a geomechanics perspective, drones, autonomy, and streamed data together enable high-resolution and confirmation of scan coverage from within stopes or beyond falls-of-ground (LKAB 2020).

Point cloud colourisation has been demonstrated for several years but is not commonly used in underground mines where lighting is inconsistent. Geomechanical applications have therefore had to rely on geometric features rather than colour. The challenge of colourisation in underground environments is compounded by the added weight and bulk of the lights and batteries. A reduction in their weight along with larger payloads on drones is bringing colourisation underground (Figure 12). The full range of applications benefitting from colourisation are yet to be explored, but obvious applications involve inspections, quality assurance and control ( $Q A / Q C)$ as well as aiding georeferencing. 


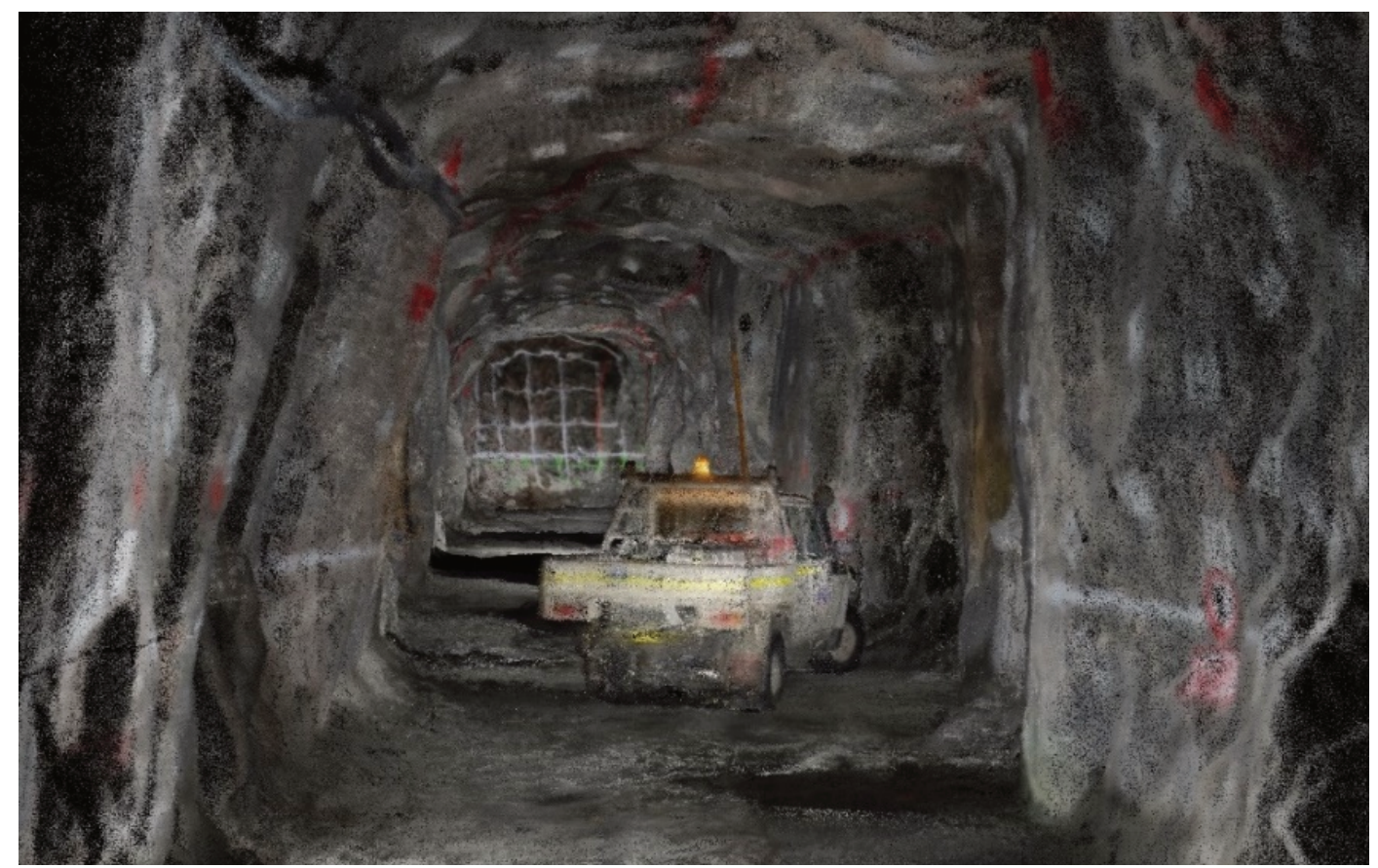

Figure 12 Coloured point cloud of an underground drive (Emesent, pers. comm. 2020)

\subsection{Point cloud data and software}

The bridge between acquisition and application is currently the bottleneck for mobile scanning's broader adoption. Resolving this bottleneck involves a trade-off between the benefits brought by point clouds and the imposition of having to learn an entirely new process and methodology to analyse them. The tipping point, where benefits exceed imposition, depends on a joint effort involving education and training, software development, and industry experience and promotion. This joint effort is beginning to shift the balance but currently, the imposition is holding the mobile LiDAR back from being an early majority monitoring methodology. Unlocking the benefits and switching the balance is not far off but has not yet been achieved.

\subsection{Future of mobile hardware and firmware}

The LiDAR sensors being used will undoubtedly improve, becoming smaller, lighter, and more accurate. Just as it is now, acquisition will exceed application; but the acquisition advancements will drive the application innovation.

The use of mobile LiDAR scanning hardware has undergone a transition from handheld devices used purely for geomechanics applications, to broadly scanning areas such as stopes, with geomechanics repurposing the data. The future will likely see another transition as LiDAR data are collected and repurposed from other remotely operated and fully autonomous platforms. Autonomous haulage vehicles will continuously acquire spatial data for their own positioning and collision avoidance purposes, as do surface autonomous vehicles. By repurposing these data, through artificial intelligence (AI) and virtual reality (VR), there is less requirement to shut operations down for inspection purposes. The higher sampling frequency in operational areas will begin transition underground excavation monitoring to something similar to open pit slope monitoring using remote sensing methods (Radar, LiDAR, or In-SAR).

As engineers become more comfortable with using point clouds, the industry will see more sensors being coupled and included in the data. There are existing sensors for 3D thermal detection (Vidas \& Moghadam 2013) and moisture detection methods (Zhang \& Zhou 2016). For geomechanics, sensors and methods such as these will lead to hydrogeological mapping. One advancement in this space will involve improved moisture content monitoring and connective pathways to moisture and water sources. 
Many of the current applications for LiDAR in underground operations are in hardrock mines, as the technology is not intrinsically safe (IS). This is changing as IS scanning options are developed such as the ExScan ${ }^{\circledast}$ case (Dunn et al. 2020) along with stand-along static scanners. As LiDAR is used more widely in coal mines, the methods from hardrock can be transferred.

\subsection{Future of point cloud data and software}

The future of point cloud use in underground geomechanics is incredibly exciting but to truly excel, it requires collaborations between industry, hardware OEMs, software developers, and research and education institutions.

It is evident through partnerships between scanning hardware companies and software providers that there is an acknowledgement and requirement to incorporate point clouds as a visualisation method within mining software. Scanning devices are here to stay, point clouds will be generated and the software used at sites will continue to adopt this visualisation methodology. The importance of this for geomechanics will be improvements in combining datasets from mining (as-built and future excavations, cave shapes and sequences), existing monitoring (seismic data, ground penetrating radar (GPR), extensometers and damage mapping etc.), and geology (lithology, alterations and structures). The ability to visualise larger point clouds enables broad-scale coverage for instability monitoring.

Many of the advantages that mobile LiDAR scanning brings to underground geomechanics are not necessarily 'new' methods, but rather expanding the coverage and scale upon which specialised local-scale tasks are currently undertaken. For instance, damage mapping will involve the comparison between two point clouds rather than schematics and qualitative damage scales. Not only will we know how much change there has been, but the coloured point cloud will show precisely how the change visibly appears. The step beyond this will involve assigning management to areas such as rehabilitation plans. Sites will be scoped, reviewed, and discussed virtually before the operator steps a foot out of the office.

\subsection{Applications for the use of mobile LiDAR in underground geomechanics}

The application of mobile LiDAR for geomechanics varies depending on whether the data is being used for an inspection (single pass), control to design (comparison between as-designed to as-mined) or monitoring (change detection between multiple point clouds). The applications are also limited by the platform required for being mobile. Some scanning devices are permanently mounted to vehicles, in which case their applications become limited. Those that are stand-alone and agnostic to the platform provide the greatest flexibility. Prior to the use of drones, mobile scanning was largely limited to accessible development, or scanning areas via tele-remote vehicles. The commercialisation of autonomous drones in 2019 has increased the areas accessible by mobile LiDAR devices. The following sections provide a high-level overview of the applications mobile LiDAR are currently being applied.

\subsubsection{Applications and literature for development excavations}

Geotechnical engineers have a responsibility of ensuring excavations remain stable providing a safe workplace. A significant portion to achieve this requires the ongoing monitoring and assessment of accessible development. The range of applications mobile LiDAR is currently being used within these areas are outlined in Table 1. Although this does not comprehensively cover all applications, it highlights technique's diversity. The references provide a starting point for further information on the applications. 
Table 1 A summary of the applications mobile LiDAR has been used in development excavations in underground geomechanics along with references to the case studies

\begin{tabular}{|c|c|c|}
\hline Application & Comments & References \\
\hline $\begin{array}{l}\text { Development pickup, } \\
\text { survey and scanning of } \\
\text { old workings }\end{array}$ & $\begin{array}{l}\text { Global accuracy currently limits their use as a } \\
\text { survey control tool, particularly over } \\
\text { extended distances. }\end{array}$ & Jones et al. (2019a) \\
\hline $\begin{array}{l}\text { Overbreak/underbreak } \\
\text { analysis }\end{array}$ & $\begin{array}{l}\text { Involves a mesh/wireframe to point cloud } \\
\text { comparison technique. }\end{array}$ & Jones et al. (2019a) \\
\hline Shotcrete thickness & $\begin{array}{l}\text { Involves a change detection method between } \\
\text { two scans. Becoming more common on spray } \\
\text { rigs. A static scanner can also be used. }\end{array}$ & Lato \& Diedrichs (2014) \\
\hline $\begin{array}{l}\text { Fall of ground or } \\
\text { seismic analysis }\end{array}$ & $\begin{array}{l}\text { The 3D point cloud provides a level of data } \\
\text { that photographs are unable to achieve. } \\
\text { Deformation data from point cloud analysis } \\
\text { coupled with geological information, seismic } \\
\text { data and numerical results provides a solid } \\
\text { basis for seismic back analysis. }\end{array}$ & $\begin{array}{l}\text { Counter (2019) } \\
\text { LKAB (2020) }\end{array}$ \\
\hline Structural mapping & $\begin{array}{l}\text { Sufficient for picking drive-scale structures. } \\
\text { Static terrestrial scanners would be more } \\
\text { appropriate for applications such as face } \\
\text { mapping. }\end{array}$ & $\begin{array}{l}\text { Gallant \& Marshall (2016) } \\
\text { Jones et al. (2019a) } \\
\text { Vallejos (2019) }\end{array}$ \\
\hline $\begin{array}{l}\text { Convergence } \\
\text { monitoring }\end{array}$ & $\begin{array}{l}\text { Mobile LiDAR provides broad coverage } \\
\text { quantitative results and is more accurate } \\
\text { than damage mapping. Various factors } \\
\text { influence the result's accuracy. }\end{array}$ & $\begin{array}{l}\text { Gelinas et al. (2019) } \\
\text { Jones \& Beck (2017) } \\
\text { Lynch et al. (2017) }\end{array}$ \\
\hline Ground support QA/QC & $\begin{array}{l}\text { An emerging application and not currently } \\
\text { widely used. }\end{array}$ & $\begin{array}{l}\text { Gelinas et al. (2019) } \\
\text { Jones et al. (2018) } \\
\text { Jones et al. (2019a) } \\
\text { Singh et al. (2019) }\end{array}$ \\
\hline $\begin{array}{l}\text { Numerical modelling } \\
\text { calibration }\end{array}$ & $\begin{array}{l}\text { Care is required as the resolution and } \\
\text { accuracy of LiDAR scans is often orders of } \\
\text { magnitude different to the scale of results } \\
\text { being interpreted. }\end{array}$ & $\begin{array}{l}\text { Counter (2019) } \\
\text { Jones et al. (2016) }\end{array}$ \\
\hline Management/TARPs & $\begin{array}{l}\text { When the monitoring method is embedded } \\
\text { into the site's systems it provides a basis for } \\
\text { decision-making. Few sites are currently at } \\
\text { this maturity of technology adoption. }\end{array}$ & $\begin{array}{l}\text { Jones \& Hancock (2019) } \\
\text { Hancock \& Jones (2019) }\end{array}$ \\
\hline Coal mines & $\begin{array}{l}\text { Mobile LiDAR are not commonly intrinsically } \\
\text { safe so their use in limited to certain areas. }\end{array}$ & $\begin{array}{l}\text { Raval et al. (2019) } \\
\text { Singh et al. (2019) }\end{array}$ \\
\hline
\end{tabular}

\subsubsection{Applications and literature for production and infrastructure excavations}

Many production and infrastructure areas have proved difficult to monitor in detail as they are largely inaccessible. For stoping mines, the use of drones as a mobile platform for LiDAR has provided geotechnical engineers access to data that has previously been inaccessible or difficult to capture at a sufficient resolution for detailed analysis. The benefits can be extended to other methods where large, inaccessible voids are created. For infrastructure inspections, mobile LiDAR provides an opportunity to rapid capture data that has previously been difficult to access. A list of the applications and relevant literature is provided in Table 2. 
Table 2 A summary of the applications mobile LiDAR has been used for production and infrastructure excavations in underground geomechanics along with references to the case studies

\begin{tabular}{|c|c|c|}
\hline Application & Comments & References \\
\hline $\begin{array}{l}\text { Stope volumes and } \\
\text { dimensions }\end{array}$ & $\begin{array}{l}\text { When used on a drone platform the } \\
\text { results are suitable as a direct } \\
\text { replacement for conventional scanning } \\
\text { methods. }\end{array}$ & $\begin{array}{l}\text { Vallejos (2019) } \\
\text { Woolmer et al. (2021) }\end{array}$ \\
\hline $\begin{array}{l}\text { Overbreak/underbreak } \\
\text { analysis }\end{array}$ & $\begin{array}{l}\text { When used on a drone platform the } \\
\text { coverage within a stope can be } \\
\text { exceptional and provide high-resolution } \\
\text { over and underbreak analysis. }\end{array}$ & $\begin{array}{l}\text { Refer to example in } \\
\text { Section 4.5.2.1 }\end{array}$ \\
\hline Structural analysis & $\begin{array}{l}\text { Remote access of stopes provides } \\
\text { excellent data to capture structural } \\
\text { information from within stope sets. This } \\
\text { information is being used for design } \\
\text { inputs and verification, rock mass } \\
\text { characterisation and geological } \\
\text { interpretation. }\end{array}$ & $\begin{array}{l}\text { Baylis \& Kewe (2020) } \\
\text { Baylis et al. (2020) } \\
\text { Vallejos (2019) } \\
\text { Woolmer et al. (2020) }\end{array}$ \\
\hline $\begin{array}{l}\text { Backfill heights and } \\
\text { volumes }\end{array}$ & $\begin{array}{l}\text { An underutilised application, particularly } \\
\text { at sites with specific backfill design } \\
\text { requirements either for plugs or for } \\
\text { mining back through later. }\end{array}$ & Jones et al. (2019a) \\
\hline $\begin{array}{l}\text { Drawpoint analysis and } \\
\text { brow monitoring }\end{array}$ & $\begin{array}{l}\text { Provides excellent 3D data for analysing } \\
\text { hangups or monitoring brow } \\
\text { deformation or breakback. }\end{array}$ & Jones et al. (2019) \\
\hline $\begin{array}{l}\text { Vertical infrastructure } \\
\text { (orepass, shafts, and } \\
\text { vent) }\end{array}$ & $\begin{array}{l}\text { The data can be used for reviewing } \\
\text { vertical profile changes, determining } \\
\text { friction factors or reviewing changes to } \\
\text { orepass shape. It is best to attach the } \\
\text { mobile LiDAR to a trolley or cable for } \\
\text { these applications. }\end{array}$ & $\begin{array}{l}\text { Jones et al. (2019a) } \\
\text { Watson \& Marshall (2018) } \\
\text { Woolmer et al. (2020) }\end{array}$ \\
\hline
\end{tabular}

\subsubsection{Stope analysis using mobile LiDAR from a drone platform}

The introduction of drones as a platform for scanning within stopes is providing unprecedented access and data for geotechnical engineering. For underground mining, the high-resolution LiDAR record of the void has been impossible to capture previously. The knowledge gained from these scans can be directly applied to:

- Orebody knowledge: structural identification and parameters such as persistence and spacing. This information can be used as parameter for rock mass characterisation and domaining.

- Rock mass behaviour: the detail in the scan provides insights into the mechanisms controlling the stope stability.

- Stope design reconciliation: the high-resolution scans provide a basis for reviewing the final stope outcomes. It is important to note, the contributing factors to the final stope shape and stability extend beyond geomechanical factors alone. The inclusion of blasting details, lithological wireframes and ground support should be considered when reviewing the outcomes. The findings from each input can be fed back into future designs.

One of the basic reconciliation descriptors is the variation of final to designed volume, reported as overbreak and underbreak. Where the stope is scanned from a cavity monitoring system (CMS), the shape formed can 
be greatly affected by shadowing. Vallejos (2019) and Baylis et al. (2020) discuss the differences between the mobile LiDAR and CMS in detail. When the variation is shown as a heatmap on a high-resolution point cloud, the spatial correlations and influence of structure become apparent (Figure 13). This example uses a point spacing of $25 \mathrm{~mm}$ and a principle components analysis comparing the as-designed wireframe to the high-resolution point cloud.

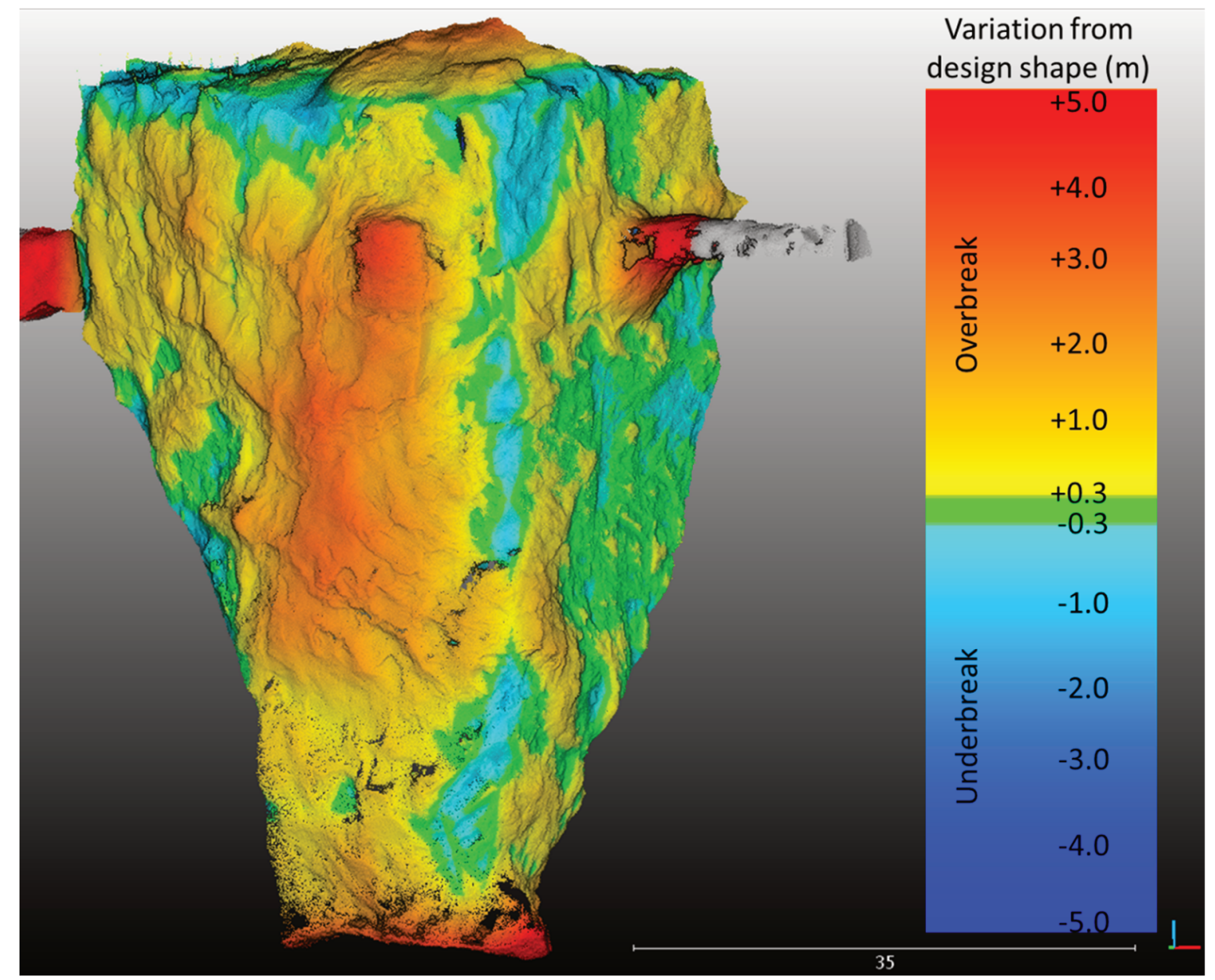

Figure 13 Example of stope over and underbreak using mobile LiDAR scanning (adapted from Baylis \& Kewe 2020)

Prior to the use of high-resolution points clouds within stopes, it has been difficult to verify the structural design parameters. The example in Figure 14 shows the structures identified within the stope as rectangular planar facets using the 'compass' tool from CloudCompare (2019). Vallejos (2019) discusses alternative methods for structure identification. The example below shows the predominant north-south striking, vertically dipping structural and the secondary east-west vertically dipping sets were both identified from window mapping used in the stope design. The window mapping shows more scatter of structure than the LiDAR picked sets, which shows a third minor set but with minimal scatter. The learning from this type of back analysis can be used to identify the predominant sets influencing the final stope shape. As this method is reproduced for multiple stopes within the same mining block, an improved knowledge of the rock mass structural characteristics is formed. Where there are discrepancies, the underlying reasons can be reviewed and may include factors such as:

- The type of structure.

- The scale of structure.

- The distance that the mapping was from the stope location. 


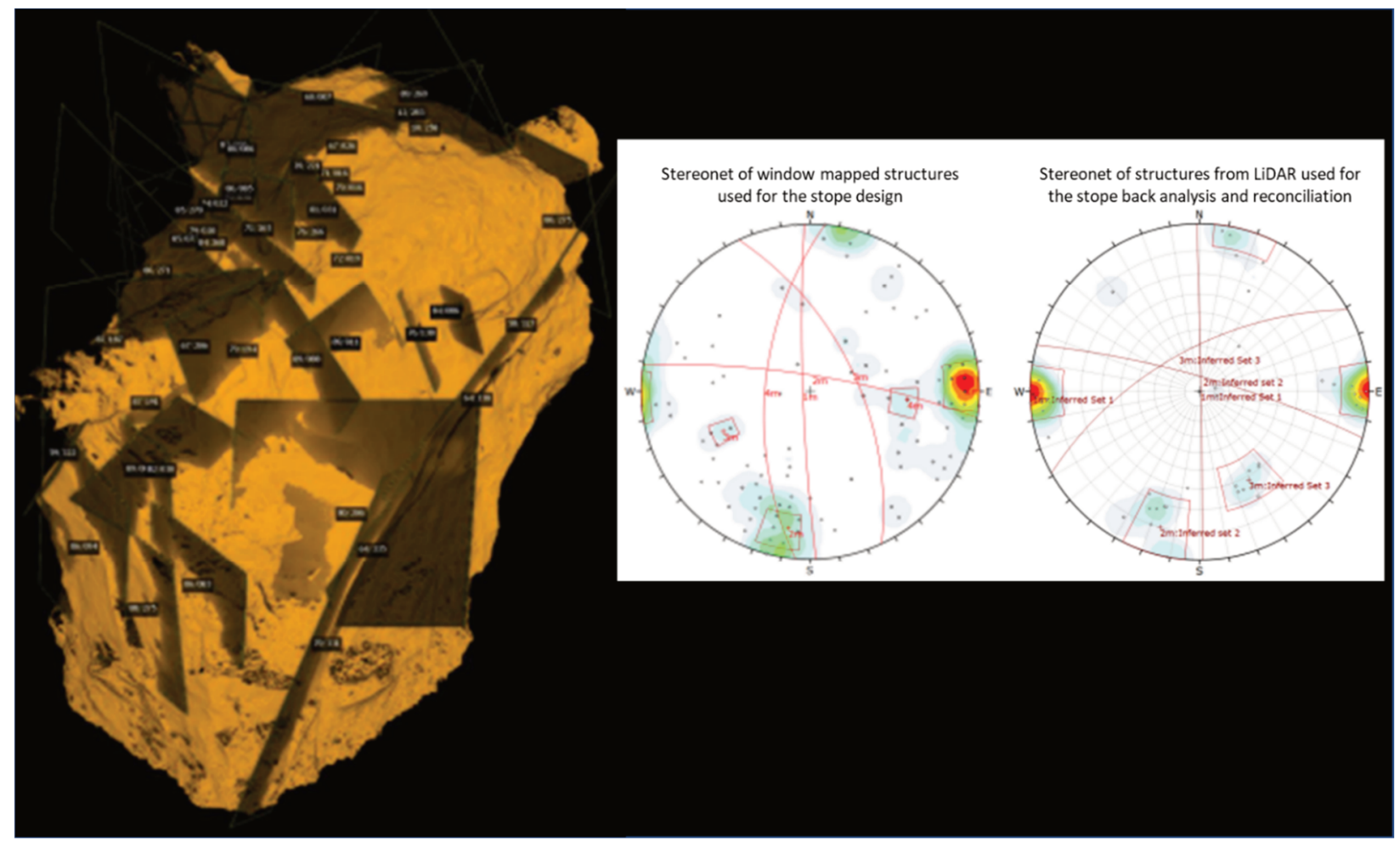

Figure 14 An example of the structures identified from a stope LiDAR point cloud. The structures used for designing the stope are summarised in the left stereonet and the structures identified from within the stope are summarised in the right stereonet (adapted from Baylis \& Kewe 2020)

Analytics from stope scanning is in its infancy and although there are already outcomes building our rock mass and stope design knowledge, there are many areas that need further research. The maturity of this method for geomechanics is very much in its innovation phase, we are leveraging the easy outcomes. Rock mass dilation rates, stope failure precursors, structure scale-dependency relationships and determination of empirical design factors (e.g. the Q parameters Ja, Jn, Jr and the Matthew's Stability Assessment B-factor).

\subsubsection{Future applications of mobile LiDAR in underground geomechanics}

Future applications of mobile LiDAR in underground geomechanics can largely be separated into two categories; entirely new, blue sky applications and the extension of existing methods such as those tabulated above.

LiDAR will play a vital role in the concept of removing people from underground mines. Currently, autonomous vehicles, robots and drones are the exception in underground environments, but we are already seeing sites (particularly block caves) where they are fully autonomous. The current problem is that these areas need shutting down for inspections. Once LiDAR data is being collected everywhere, from all vehicles, robots, and strategically placed drones, point clouds will be used for remote inspection purposes. At the time of writing, Emesent Pty Ltd released footage showing a drone flying underground in Canada remotely operated from their Brisbane office. This concept is not limited to intercontinental flights, rather it could involve the deployment of a pre-placed drone or robot from the surface to conduct a remote inspection (i.e. a blast clearance or following a seismic event). Combining current analytical methods with point cloud colourisation and VR would enable geotechnical engineers to conduct quantitative assessments and visual inspections without having to step foot underground exposing themselves to potential hazards.

The concept of remote, automated data acquisition is already applied to surface mining through services provided by companies such as Airobotics Pty Ltd. Future, fully-automated underground drone-in-a-box solutions will mean acquisition frequency will increase and their self-contained nature allows for their placement within hazard and exclusion zones. 
Extending existing applications does not necessarily mean new methods, but rather improving the user-friendliness of extracting information and integrating this into a decision-making process. The other aspect to extending current applications is collating various applications in such a way that the many small observations can identify the emergence of a larger-scale event. This reiterates the concepts presented earlier in the paper.

\section{Conclusion}

It has taken over 60 years of LiDAR research and development to enable rapid and comprehensive scanning of underground excavations, much of which has occurred over the past decade with GPS-denied mobile LiDAR development. Mobile LiDAR results have been successfully applied to a range of underground, hardrock geomechanics applications. Although it is yet to become a 'standard' technique, it will undoubtedly continue to advance and become mainstream. Its adoption to underground mining has advanced our knowledge beyond geomechanics, and is now being used for survey, geology, mining engineering and ventilation.

The method's true potential arises as one of the few techniques capable of providing three-dimensional, spatially continuous coverage of underground excavations. Just as open pit radar and LiDAR has advanced the monitoring and forecasting of pit wall stability, mobile LiDAR has the potential to bring similar concepts to underground mining. With conventional underground monitoring methods, the spatial sampling density and temporal frequency often limit the ability to recognise multiple, small, connected changes and trends in datasets that are indications of a larger emerging instability. LiDAR data's continuity, coverage, accuracy and rapid acquisition significantly advance the ability to measure change over large areas and provides a basis for connecting multiple observational datasets.

The introduction of mobile LiDAR scanning to underground geomechanics, and mining more generally, has three main challenges; new complex hardware, data handling techniques, and methods to apply the information back into operations. The past decade has shown that the hardware has, and will continue, to lead the evolution. Acquisition is not the bottleneck, but it does simplify the downstream workflows as acquisition and processing becomes easier and results become more accurate. Data handling has been a major bottleneck with challenges at multiple levels. As LiDAR becomes more prevalent in all industries, the methods to visualise, store, and manipulate data improves these challenges are being overcome. Introducing these into mining workflows have more recently seen advancements. Although there is no single 'go-to' package, it is unlikely that the main bottleneck will remain the data handling and will shift to a site's willingness to adopt and implement scanning as a fundamental monitoring technique.

Despite mobile LiDAR's upside in underground geomechanics, it must be remembered that it is not a sole-source solution. The true benefits to geotechnical engineering come from coupling multiple data sources, be this seismic data, GPR, extensometers, or damage mapping.

What can be concluded is that mobile LiDAR will stay in the industry. How it is acquired, stored, used, and applied will not stop evolving. Arp et al. (1982) developed a process that took five months to do (it took 34 years to do the year prior). Had he waited for commercial GPS, this would have been reduced further. Nowadays, this same process is conducted from space in a matter of seconds. Mobile LiDAR in underground geomechanics is undertaking a comparative pathway. Where the same sampling density and coverage would have taken years to achieve prior to mobile LiDAR, it is now measured in minutes and days.

In the not-too-distance future, mining will not be able to be conducted without it as it will provide the guidance for autonomous trucks and loaders, will be used for remote damage mapping, and form the basis for remote visual inspections. The requirement now is for sites to familiarise themselves with the technology, data, and methods for applications. Without it, we are holding ourselves back put operations and personnel at risk by mining blind. 


\section{Acknowledgement}

The past six years have involved the trust and guidance of my PhD supervisors, David Beck and Ernesto Villaescusa. David has been on this journey every step with me and for this I am profoundly grateful.

\section{References}

Arp, H, Greisbach, JC \& Burns, JP 1982, 'Mapping in tropical forests: a new approach using the laser APR', Photogrammetric Engineering and Remote Sensing, vol. 48, no. 1, pp. 91-100.

Artan, U, Marshall, J \& Lavigne, N 2011, Robotic mapping of underground mine passageways', Mining Technology, vol. 120, pp. 18-24, https://doi.org/10.1179/1743286311Y.0000000001

Baylis, C \& Kewe, D 2020, New technologies and methods for rock mass characterisations and domining, presentation at East Australian Geomechanics Group, Adelaide.

Baylis, C, Kewe, D \& Jones, E 2020, 'Mobile drone LiDAR structural data collection and analysis', in J Wesseloo (ed.), Proceedings of the Second International Conference on Underground Mining Technology, Australian Centre for Geomechanics, Perth, pp. 325-334.

Bosse, M \& Zlot, R 2009, 'Continuous 3D scan-matching with a spinning 2D laser', Proceedings of the IEEE International Conference on Robotics and Automation, Institute of Electrical and Electronics Engineer, Piscataway.

CloudCompare 2019, 3D point cloud and mesh processing software, computer software, version 2.9, http://www.cloudcompare.org/ Counter, DB 2019, 'Laser-based scanning to manage geotechnical risk in deep mines', in J Hadjigeorgiou \& M Hudyma (eds), Proceedings of the Ninth International Symposium on Ground Support in Mining and Underground Construction, Australian Centre for Geomechanics, Perth, pp. 43-58, https://doi.org/10.36487/ACG_rep/1925_01_Counter

DARPA 2020, Subterranean Challenge, accessed 10 October 2020, https://www.subtchallenge.com/\#icons

Drover, C \& Villaescusa, E 2015, 'Estimation of dynamic load demand on a ground support scheme due to a large structurally controlled violent failure - a case study', Mining Technology, vol. 125, pp. 1-14, https://doi.org/10.1179/1743286315Y.0000000029

Duff, E 2016, Zebedee, accessed 17 September 2020, https://confluence.csiro.au/display/ASL/Zebedee

Dunn, M, Reid, P \& Malos, J 2020, 'Development of a protective enclosure for remote sensing applications-case study: laser scanning in underground coal mines', Resources, vol. 9, no. 5, https://doi.org/10.3390/resources9050056

Durrant-Whyte, H \& Bailey, T 2006, 'Simultaneous Localisation and Mapping (SLAM): Part I The Essential Algorithms', IEEE Robotics \& Automation Magazine, vol. 13, issue 2, pp. 99-110.

Gallant, M \& Marshall, JA 2016, 'Automated rapid mapping of joint orientations with mobile LiDAR', International Journal of Rock Mechanics and Mining Sciences, vol. 90, pp. 1-14.

Gelinas, LP, Falmagne, V, Bedard, B \& Matte, O 2019, 'Advanced geotechnical monitoring technology to assess ground support effectiveness', in J Hadjigeorgiou \& M Hudyma (eds), Proceedings of the Ninth International Symposium on Ground Support in Mining and Underground Construction, Australian Centre for Geomechanics, Perth, pp. 59-74, https://doi.org/10.36487/ACG_rep/1925_02_Gelinas

Hancock, E \& Jones, E 2019, 'Budgeting for deformation', in SAB da Fontoura, RJ Rocca \& JO Mendoza (eds), Rock Mechanics for Natural Resources and Infrastructure Development - Full Papers; Proceedings of the 14th International Congress on Rock Mechanics and Rock Engineering, CRC Press, London, pp. 1433-1441.

Hickman, GD \& Hogg, JE 1969, 'Application of an airborne pulsed laser for near shore bathymetric measurements', Remote Sensing of Environment, vol. 1, pp. 47-58, https://doi.org/10.1016/S0034-4257(69)90088-1

Jiao, Y \& Hudson, JA 1995, 'The fully-coupled model for rock engineering systems', International Journal of Rock Mechanics and Mining Sciences \& Geomechanics Abstracts, vol. 32, pp. 491-512.

Jones, E \& Beck, D 2017, 'The use of 3D laser scanning for deformation monitoring in underground mines', Proceedings of the 13th AusIMM Underground Operators' Conference, The Australasian Institute of Mining and Metallurgy, Melbourne, pp. 267-270.

Jones, E \& Hancock, E 2019, 'Managing the deformation of ground support and reinforcement', Rock Mechanics for Natural Resources and Infrastructure Development - Full Papers; Proceedings of the 14th International Congress on Rock Mechanics and Rock Engineering, CRC Press, London, pp. 822-830.

Jones, E, Beck, D \& Reusch, F 2016, 'The use of underground laser mapping for numerical model calibration', Proceedings of EUROCK 2016, International Society of Rock Mechanics, Lisbon, pp. 1237-1242, https://www.onepetro.org/conference-paper/ISRMEUROCK-2016-200

Jones, E, Ghabraie, B \& Beck, D 2018, 'A method for determining field accuracy of mobile scanning devices for geomechanics applications', Proceedings of the 10th Asian Rock Mechanics Symposium, International Society for Rock Mechanics and Rock Engineering, Lisbon.

Jones, E, Reardon, D \& Hrabar, S 2019a, 'The use of automated drones in underground hard rock mines', Proceedings Future Mining 2019, The Australasian Institute of Mining and Metallurgy, Melbourne, pp. 34-46.

Jones, E, Sofonia, J, Canales, C, Hrabar, S \& Kendoul, F 2019b, 'Advances and applications for automated drones in underground mining operations', in W Joughin (ed.), Proceedings of the Ninth International Conference on Deep and High Stress Mining, The Southern African Institute of Mining and Metallurgy, Johannesburg, pp. 323-334, https://doi.org/10.36487/ACG_rep/1952_24_Jones 
Lato, M \& Diederichs, M 2014, 'Mapping shotcrete thickness using LiDAR and photogrammetry data: Correcting for over-calculation due to rockmass convergence', Tunnelling and Underground Space Technology, vol. 41, pp. 234-240, https://doi.org/10.1016/j.tust.2013.12.013

LKAB 2020, 'One month after the seismic event in the Kiruna Mine', LKAB news, viewed 12 October 2020, https://www.lkab.com/en/news-room/news/one-month-after-the-seismic-event-in-the-kiruna-mine/

Lynch, B, Marr, J, Marshall, J \& Greenspan, M 2017, 'Mobile LiDAR-based convergence detection in underground tunnel environments', https://qspace.library.queensu.ca/bitstream/handle/1974/15638/Lynch_et_al_2017_Mobile_LIDAR.pdf? sequence $=1 \&$ isAllowed=y

Maiman, T 1960, 'Stimulated optical radiation in ruby', Nature, vol. 187, no. 4736, pp. 493-494, https://doi.org/10.1038/187493a0

Nelson, R 2014, 'How did we get here? An early history of forestry lidar 1', Canadian Journal of Remote Sensing, vol. 39, pp. S6-S17, https://doi.org/10.5589/m13-011

Nuchter, A, Surmann, H, Lingemann, K, Hertzberg, J \& Thrun, S 2004, '6D SLAM with an application in autonomous mine mapping', Proceedings of the IEEE International Conference on Robotics and Automation, https://doi.org/10.1109/ROBOT.2004.1308117

Peck, RB 1969, 'Advantages and limitations of the observational method in applied soil mechanics', Géotechnique, vol. 19, issue 2, pp. 171-187.

Raval, S, Banerjee, B, Canbulat, I \& Singh, SK 2019, 'A preliminary investigation of mobile mapping technology for underground mining', Proceedings of the IEEE International Geoscience and Remote Sensing Symposium, https://doi.org/10.1109/IGARSS.2019.8898518

Reeves, B, Noon, D, Stickley, G \& Longstaff, I 2001, 'Slope stability radar for monitoring mine walls', in C Nguyen (ed.), Proceedings of Subsurface and Surface Sensing Technologies and Applications III, https://doi.org/10.1117/12.450188

Rogers, EM 1962, Diffusion of innovations, Free Press of Glencoe, New York.

Ross, B 2017, Rise to the Occasion: Lessons from the Bingham Canyon Manefay Slide, Society for Mining, Metallurgy \& Exploration, Englewood.

Singh, SK, Raval, S \& Banerjee, BP 2019, 'Mobile 3D imaging in underground coal mines: a case study', Proceedings of Future Mining 2019, The Australasian Institute of Mining and Metallurgy, Melbourne, pp. 145-148.

Szwedzicki, T 2001, 'Geotechnical precursors to large-scale ground collapse in mines', International Journal of Rock Mechanics and Mining Sciences, vol. 38, pp. 957-965, https://doi.org/10.1016/S1365-1609(01)00062-4

Szwedzicki, T 2003, 'Rock mass behaviour prior to failure', International Journal of Rock Mechanics and Mining Sciences, vol. 40, pp. 573-584, https://doi.org/10.1016/S1365-1609(03)00023-6

Tversky, A \& Kahneman, D 1974, 'Judgment under uncertainty: heuristics and biases', Science, vol. 185, issue 4157, pp. 1124-1131, http://www.jstor.org/stable/1738360

Vallejos, C 2019, Structural recognition and rock mass characterisation in underground mines: a UAV and LiDAR mapping based approach, MSc thesis, Universidad De Concepcion, Santiago.

Vidas, S \& Moghadam, P 2013, 'HeatWave: A handheld 3D thermography system for energy auditing', Energy and Buildings, vol. 66, pp. 445-460, http://dx.doi.org/10.1016/j.enbuild.2013.07.030

Watson, C \& Marshall, J 2018, 'Estimating underground mine ventilation friction factors from low density 3D data acquired by a moving LiDAR', International Journal of Mining Science and Technology, vol. 28, https://doi.org/10.1016/j.ijmst.2018.03.009

Woolmer, D, Jones, E, Taylor, J, Baylis, C \& Kewe, D 2021, 'Use of drone-based LiDAR technology at Olympic Dam mine and Initial technical applications', Proceedings of the Eighth International Conference \& Exhibition on mass Mining, submitted for publication.

Zhang, D \& Zhou, G 2016, 'Estimation of soil moisture from optical and thermal remote sensing: a review', Sensors, vol. 16, issue 8, https://doi.org/10.3390/s16081308

Zlot, R \& Bosse, M 2012, 'Efficient large-scale 3D mobile mapping and surface reconstruction of an underground mine', Field and Service Robotics, vol. 92, https://doi.org/10.1007/978-3-642-40686-7_32 